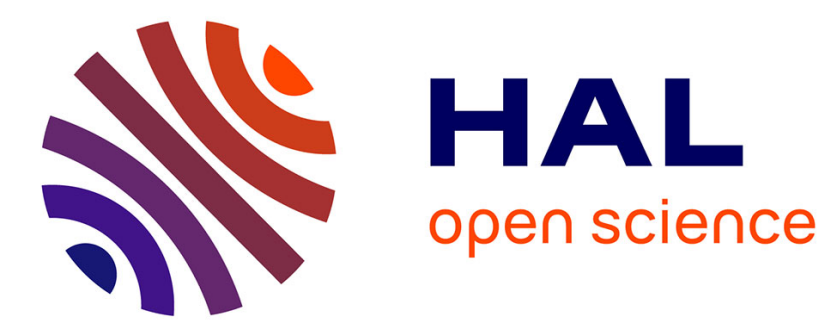

\title{
Polymorphism of crystalline complexes of V-amylose with fatty acids
}

Cong-Anh-Khanh Le, Luc Choisnard, Denis Wouessidjewe, Jean-Luc Putaux

\section{To cite this version:}

Cong-Anh-Khanh Le, Luc Choisnard, Denis Wouessidjewe, Jean-Luc Putaux. Polymorphism of crystalline complexes of V-amylose with fatty acids. International Journal of Biological Macromolecules, 2018, 119, pp.555-564. 10.1016/j.ijbiomac.2018.07.163 . hal-02106133

\section{HAL Id: hal-02106133 \\ https://hal.science/hal-02106133}

Submitted on 25 Feb 2021

HAL is a multi-disciplinary open access archive for the deposit and dissemination of scientific research documents, whether they are published or not. The documents may come from teaching and research institutions in France or abroad, or from public or private research centers.
L'archive ouverte pluridisciplinaire HAL, est destinée au dépôt et à la diffusion de documents scientifiques de niveau recherche, publiés ou non, émanant des établissements d'enseignement et de recherche français ou étrangers, des laboratoires publics ou privés. 


\title{
Polymorphism of crystalline complexes of $\mathrm{V}$-amylose with fatty acids
}

\author{
Cong-Anh-Khanh Le ${ }^{\mathrm{a}}$, Luc Choisnard ${ }^{\mathrm{b}}$, Denis Wouessidjewe ${ }^{\mathrm{b}}$, Jean-Luc Putaux ${ }^{\mathrm{a} *}$ \\ ${ }^{a}$ Univ. Grenoble Alpes, CNRS, CERMAV, F-38000 Grenoble, France \\ ${ }^{b}$ Univ. Grenoble Alpes, CNRS, DPM, F-38000 Grenoble, France
}

* corresponding author: jean-luc.putaux@cermav.cnrs.fr

Published in: International Journal of Biological Macromolecules 119 (2018) 555-564 DOI: doi.org/10.1016/j.ijbiomac.2018.07.163 


\begin{abstract}
The crystallization of amylose from dilute solutions in the presence of a series of linear saturated fatty acids ( $\mathrm{C} 3$ to $\mathrm{C} 20)$ was investigated by varying the fatty acid concentration, crystallization temperature and solvent composition (DMSO:water in various ratios). The morphology and structure of the resulting model lamellar crystals were characterized by transmission electron microscopy as well as electron and X-ray diffraction. By adequately controlling the crystallization parameters, all fatty acids could induce the formation of both 6- and 7-fold Vamylose single helices, indicating that the amylose conformation was independent of the chain length of the complexing molecule. Three allomorphs (V6 $\mathrm{I}, \mathrm{V} 6_{\mathrm{II}}$ and $\mathrm{V} 7$ ) were identified individually or in mixtures. Higher concentrations of fatty acid and DMSO and a higher temperature promoted the formation of the more compact $V 6_{I}$ structure. $V 6_{\text {II }}$ and $V 7$ preferentially formed with lower concentrations of fatty acids and DMSO and at lower temperatures. In the case of C5-C20 fatty acids, V7 was only obtained in the presence of DMSO. The polymorphism of $\mathrm{V}$-amylose complexes with linear saturated fatty acids thus appears to be a more general phenomenon than previously reported in the literature.
\end{abstract}

\footnotetext{
Abbreviations:

PROA: propanoic acid (C3); BUTA: butanoic acid (C4); PENA: pentanoic acid (C5); HEXA: hexanoic acid (C6); OCTA: octanoic acid (C8); DECA: decanoic acid (C10); DODA: dodecanoic acid C12); TEDA: tetradecanoic acid (C14); HEDA: hexadecanoic acid (C16); OCDA: octadecanoic acid (C18); ICOA: icosanoic acid (C20); DP: degree of polymerization; TEM: transmission electron microscopy; ED: electron diffraction; XRD: X-ray diffraction.
} 


\section{Introduction}

Amylose, a constituent of starch, is a mostly linear polymer consisting of $\alpha$-D-glucose units connected by $\alpha(1 \rightarrow 4)$ bonds with less than $1 \% \alpha(1 \rightarrow 6)$ branching linkages [1]. The linear nature of the chain and the torsion angles around the osidic linkage promote helical molecular trajectories. Amylose can be crystallized in vitro from aqueous solutions into so-called A- and B-type allomorphs that both consist of the parallel packing of 6-fold left-handed double helices associated with a number of water molecules [2,3].

Amylose also exists as single helices when it crystallizes in the presence of a variety of organic and inorganic molecules [4-8]. The resulting inclusion compounds, known under the generic name of V-amylose, are generally crystallized from aqueous solutions $[9,10]$. In the literature, several types of $\mathrm{V}$-amylose have been reported that can readily be distinguished by their X-ray diffraction (XRD) powder pattern. In addition, transmission electron microscopy (TEM) has significantly contributed to the morphological and structural characterization of V-amylose lamellar single crystals prepared from dilute solutions. Since the helical axis of amylose is perpendicular to the approximately $10 \mathrm{~nm}$-thick lamellae, base-plane electron diffraction (ED) patterns were particularly helpful to identify the different crystal systems [11, 12]. Depending on the guest molecule, the single helices can be made of 6,7 or 8 glucosyl units per turn, organized into different unit cells. $V_{\mathrm{H}}$ crystals prepared in the presence of ethanol [13] or fatty acids [14] are hexagonal. They contain left-handed 6-fold helices, the organization of which has been described using orthorhombic $[5,15]$ or hexagonal $[13,16]$ unit cells. Six-fold helices have also been reported to occur in other types of crystals prepared with iodine [6], $n$ butanol [17], dimethyl sulfoxide [18], ethylenediamine [19] and glycerol [20]. Bear [4] suggested that bulkier molecules would be accommodated in a helix with a larger cross-section, i.e. with more residues per turn. Zaslow [21] compared the volume of the pseudo-hexagonal unit cells of the partially dried complexes formed with tert-butanol and $n$-butanol and obtained a ratio of about 7:6 in favor of the existence of a 7-fold helix for $\mathrm{V}_{\text {tert-butanol. }}$ Yamashita and Hirai confirmed this observation by preparing crystals with branched alcohols larger than $n$-butanol [22]. V-amylose crystals prepared in the presence of 2-propanol have a rectangular shape and an orthorhombic unit cell [23,24]. Although models based on 6- and 7-fold helices have both been proposed [22, 23], using a combination of structure refinement based on conformational and packing energy analyses with classical crystalline polymer structure refinement, Nishiyama et al. have shown that the 7-fold conformation was the most probable [25]. Finally, when crystallized with 1-naphthol or quinoline, amylose forms square single crystals corresponding to a tetragonal organization of 8 -fold helices [26]. 
The complexes of starch with fatty acids have been particularly studied since both types of molecules coexist and interact in some native starch granules [27] and in a large variety of processed food [28-30]. Various formulations and processing methods have been tested [31-33] to develop products with potential health benefits [34]. Linear saturated fatty acids form crystalline complexes with amylose from aqueous solutions [14,35]. Several electron diffraction (ED) and X-ray diffraction (XRD) studies have reported that the complexes corresponded to the $\mathrm{V}_{\mathrm{H}}$-type regardless of the fatty acid chain length (C8-C18) $[5,11,33,36]$. Some authors classified complexes of amylose with fatty acids into different types (I, IIa and IIb) based on thermal behaviors. However, the XRD profiles showed that they all corresponded to the $\mathrm{V}_{\mathrm{H}}$ allomorph but mostly differed by their degree of crystallinity [33,37,38]. Studying complexes with shortchain fatty acids, Takeo et al. [16] revealed that by varying the water/propionic acid ratio, amylose could crystallize into different allomorphs that would contain 6- or 7-fold helices, organized into hexagonal or orthorhombic unit cells, respectively. After this first evidence of polymorphism of $\mathrm{V}$-amylose with a given fatty acid, only a few examples have been documented. Helbert [35] reported that butanoic acid (C4) could also induce both 6- or 7-fold helices. Hexanoic acid (C6) was also shown to yield crystals with a $V_{H}$ structure [35] as well as a second arrangement of 6-fold helices, isomorphous to that observed with complexes with $n$-butanol [17,39].

The $\mathrm{V}_{\text {fatty acids }}$ complexes have frequently been used as models to study various characteristics and properties of $\mathrm{V}$-amylose: morphology and crystal structure $[5,16,35,36]$, physicochemical properties [37,40-44], enzymatic hydrolysis and digestibility [40,45-47], encapsulation and release properties $[36,48,49]$ as well as complexation protocols and factors affecting the crystallization $[38,47,50]$.

Since some fatty acids (propanoic, butanoic and hexanoic acids) have been reported to yield different crystalline forms, it seemed likely that polymorphism would also be observed with other linear fatty acids of the homologous series, using suitable crystallization conditions. In order to shed some light on the parameters that control the polymorphism of the $\mathrm{V}_{\text {fatty acid }}$ complexes, we have investigated the crystallization of amylose in dilute aqueous solution with a series of saturated linear fatty acids of increasing length from C3 to C20. The morphology and structure of the resulting lamellar crystals were characterized by TEM, ED and XRD.

\section{Experimental}

\subsection{Amylose and fatty acids}

Potato amylose was purchased from Sigma-Aldrich and further purified as previously reported [35]. Briefly, $30 \mathrm{~g}$ of amylose was dissolved in $1 \mathrm{~L}$ of dimethyl sulfoxide (DMSO) by 
stirring for $12 \mathrm{~h}$ at room temperature. The solution was centrifuged $(2500 \mathrm{~g}, 20 \mathrm{~min})$ to remove residual aggregates. Amylose was precipitated by addition of an equal volume of ethanol, kept at $4{ }^{\circ} \mathrm{C}$ for $12 \mathrm{~h}$, filtered (glass filter G5) and extensively rinsed with ethanol, acetone and diethyl ether, successively, using a Büchner device hooked to a water suction pump. Amylose was then dried for one week in an exhaust hood at room temperature. A series of fatty acids was purchased from Sigma-Aldrich: propanoic acid (referred to as PROA - C3), butanoic acid (BUTA - C4), pentanoic acid (PENA - C5), hexanoic acid (HEXA - C6), octanoic acid (OCTA - C8), decanoic acid (DECA - C10), dodecanoic acid (DODA - C12), tetradecanoic acid (TEDA - C14), octadecanoic acid (OCDA - C18) and icosanoic acid (ICOA - C20).

\subsection{Crystallization protocols}

Aqueous amylose dispersions $(0.1 \mathrm{wt} \%)$ were submitted to nitrogen bubbling for $20 \mathrm{~min}$ and autoclaved in an oil bath at $160{ }^{\circ} \mathrm{C}$ for $30 \mathrm{~min}$. In other tests, amylose solutions were prepared by dissolving amylose in DMSO at $100{ }^{\circ} \mathrm{C}$, then diluting with boiling water to the desired concentration ( $0.1 \mathrm{wt} \%$ amylose). Two and $10 \mathrm{vol} \%$ DMSO were tested. The concentration of fatty acids varied depending on their chain length and physical state: 5-50 vol\% for $\mathrm{C} 3$ and $\mathrm{C} 4$ (water-miscible liquids), 2.5-5.0 vol\% for C5 (water-immiscible liquid), and saturation concentration for C6 to C20 (poorly water-soluble liquids or solids). Preheated liquid fatty acids were mixed with amylose solutions at $90{ }^{\circ} \mathrm{C}$, while solid fatty acids were added either before or after the dissolution of amylose. The mixtures were then kept at a predetermined temperature (between 40 and $90{ }^{\circ} \mathrm{C}$, depending on the fatty acid) for one week or slowly cooled down to room temperature in a Dewar bottle initially filled with boiling water. In the case of watermiscible fatty acids, the resulting crystals were stored in their mother liquor. For waterimmiscible fatty acids, the excess of liquid floating on top of the dispersions was removed by pipetting. The excess of insoluble solid fatty acids was removed by washing the wet solid fraction of the decanted dispersion three times with diethyl ether.

\section{3. $X$-ray diffraction $(X R D)$}

The crystal suspensions were centrifuged and the excess solvent was removed. The pellets were deposited on a $7-\mu \mathrm{m}$ nylon bolting cloth, equilibrated over a salt-saturated aqueous solution with 95\% relative humidity (RH). Fragments of the resulting films were inserted into $1.0 \mathrm{~mm}$ (outer diameter) X-ray glass capillaries which were immediately flame-sealed. The specimens were X-rayed in vacuum by a Ni-filtered $\mathrm{CuK} \alpha$ radiation $(\lambda=0.15418 \mathrm{~nm})$ using a Philips PW3830 generator operating at $30 \mathrm{kV}$ and $20 \mathrm{~mA}$, equipped with a Wahrus camera. Twodimensional diagrams were recorded on Fujifilm image plates over 2-h exposures and read with 
a Fujifilm BAS 1800-II bioimaging analyzer. The 2D diffraction diagrams were rotationally averaged to obtain diffraction profiles that were normalized between 5 and $30^{\circ}(2 \theta)$. The XRD data were calibrated using the diffraction pattern of calcite $\left(\mathrm{CaCO}_{3}\right)$ powder and the cell parameters were calculated using the CelRef module (version 3) of the LMGP package [51].

\subsection{Transmission electron microscopy (TEM) and electron diffraction (ED)}

Drops of dilute crystal suspensions were deposited on glow-discharged carbon-coated grids and allowed to dry. The specimens were observed under low dose illumination with a FEI-Philips CM200 'Cryo' microscope operating at $200 \mathrm{kV}$. For electron diffraction, the TEM grids were mounted on a Gatan 626 specimen holder and fast-frozen into liquid nitrogen just after air drying and prior to being introduced in the microscope. The holder was then cooled down with liquid nitrogen and the crystals were observed under low dose illumination at low temperature (-177 $\left.{ }^{\circ} \mathrm{C}\right)$. Base-plane electron diffraction patterns were recorded from selected areas of about $1 \mu \mathrm{m}^{2}$. Images and diffraction patterns were recorded with a TVIPS TemCam F216 camera. The diffraction patterns were calibrated using a gold-coated carbon film as standard.

\section{Results}

In the following, we will refer to three distinct allomorphs of $\mathrm{V}$-amylose, using a notation based on that proposed by Helbert [35]. The compact hexagonal packing of 6-fold helices obtained with linear alcohols [13] and fatty acids [14], often called "V $\mathrm{V}_{\mathrm{H}}$ ", will be referred to as "V6 $6_{\mathrm{I}}$ " whereas the structure proposed by Helbert and Chanzy [17] to describe $\mathrm{V}_{\mathrm{n} \text {-butanol }}$ or $\mathrm{V}_{\mathrm{n} \text {-pentanol }}$ crystals will be called "V6II". While Zaslow [21] had modeled the unit cell of complexes prepared with tertbutanol using 7-fold helices, Buléon et al. [23] later proposed an alternate model based on 6-fold helices to describe the structure of similar crystals prepared with 2-propanol or acetone, hence the "V6 $6_{\text {III" }}$ denomination that can be found in some articles [9,39,52]. However, Nishiyama et al. [25] have recently demonstrated that the constituting helices were more likely 7-fold. Consequently, we will use the notation "V7" in the following sections.

\subsection{Morphology and structure of individual allomorphs}

Depending on the crystallization conditions (solvent, temperature, etc.), three basic types of lamellar crystals were distinguished, individually or in mixtures, according to their crystallization pattern, morphology and crystal structure, although for each type, some minor variations in shape were observed.

The first type exhibited a characteristic hexagonal morphology and occurred as individual lamellae or, more frequently, stacks of lamellae involving spiral dislocation growth. Examples 
of such crystals are shown in Figure 1a-d but hexagonal crystals were obtained with the whole series of fatty acids (Supplementary Data Figure S1). The base-plane ED patterns recorded on frozen-hydrated crystals were all hexagonal (Figure 1e, Supplementary Data Figure S2) and were indexed on the basis of a hexagonal unit cell with parameters $a=b=1.36 \pm 0.02 \mathrm{~nm}$ or an orthorhombic unit cell with $a=1.36 \pm 0.02 \mathrm{~nm}$ and $b=a \sqrt{3}=2.36 \pm 0.03 \mathrm{~nm}$ (Supplementary Data Table S1). The XRD powder patterns recorded from crystals equilibrated at $95 \% \mathrm{RH}$ were all identical as well (Figure 1f, Supplementary Data Figure S7) and could be indexed along a hexagonal unit cell. The parameters calculated for the whole series of fatty acids are given in Supplementary Data Table S2. The average parameters of the hexagonal unit cell are $a=b=1.37 \pm 0.01 \mathrm{~nm}$ and $c=0.81 \pm 0.01 \mathrm{~nm}$, and $a=1.37 \pm 0.01, b=a \sqrt{3}=2.38 \pm 0.01 \mathrm{~nm}$ and $c=0.81 \pm 0.01 \mathrm{~nm}$ for the orthorhombic unit cell. The reflection indices are provided for one example ( $\left.\mathrm{V}_{\mathrm{PENA}}\right)$ in Supplementary Data Table S3. All these hexagonal crystals thus belong to the V6I family [13].

In addition, two types of rectangular crystals were observed. The first one consisted of elongated particles made of several lamellae stacked on their base plane, most likely via epitaxial growth (Figure 2, Supplementary Data Figure S3). $60^{\circ}$ and $90^{\circ}$ twinned assemblies were frequently observed (Figure 2b-d). This type of crystals was obtained with all fatty acids of the series except PROA. The XRD patterns recorded from hydrated powders clearly corresponded to the orthorhombic V6 II allomorph, with average cell parameters $a=2.64 \pm 0.01 \mathrm{~nm}, b=2.70$ $\pm 0.01 \mathrm{~nm}$ and $c=0.81 \pm 0.00 \mathrm{~nm}$ (Figure 2f, Supplementary Data Tables S2 and S3, and Figure S7). However, base-plane ED patterns corresponding to the V6 II structure were particularly elusive as it was difficult to prevent a partial drying during the preparation of TEM specimens. When the structure was preserved, the two-dimensional orthorhombic lattice of the base-plane ED pattern was unambiguously identified as that of the V6 II allomorph, with parameters $a=2.65$ $\pm 0.01 \mathrm{~nm}$ and $b=2.68 \pm 0.01 \mathrm{~nm}$. (Figure 2e, Supplementary Data Figure S4 and Table S1). The crystals are thus isomorphous to those prepared in the presence of $n$-butanol or $n$-pentanol $[17,35,53,54]$. However, for consistency with the other V-amylose allomorphs and following the convention proposed by Donnay [55], i.e. $a<b$, we have switched the $a$ and $b$ values with respect to those given in the previous studies. The ED pattern of partially dried specimens was an intermediate between those of V6 $6_{\text {I }}$ and V6 $6_{\text {II }}$ (Supplementary Data Figure S4), in agreement with the observation of Helbert and Chanzy [17] that V6 II converts into V6I upon air-drying. Moreover, a characteristic feature of the $\mathrm{V}_{\text {II }}$ crystals was the longitudinal cracks that occurred upon drying. As described by Helbert and Chanzy [17], these cracks appear upon drying due to the $\mathrm{V}_{\text {II }}$ to $\mathrm{V} 6_{\text {I }}$ transition that involves a reorganization of the amylose helices within the lattice. 
The second type of rectangular lamellar crystals generally grew in the form of more or less dense flower-like aggregates (Figure 3, Supplementary Data Figure S5) and were obtained with all fatty acids. Although this type of complex was easily identified from this typical crystal organization, base-plane ED patterns could only be recorded when the single lamellae were sufficiently individualized at the periphery of the aggregates or from broken lamellae (Figure 3e, Supplementary Data Figure S6). The ED patterns were indexed in a two-dimensional orthorhombic unit cell with parameters $a=2.82 \pm 0.03 \mathrm{~nm}$ and $b=2.94 \pm 0.07 \mathrm{~nm}$ (Supplementary Data Table S1), in good agreement with those calculated from XRD powder patterns $(a=2.80 \pm 0.01 \mathrm{~nm}, b=2.97 \pm 0.01 \mathrm{~nm}$ and $c=0.80 \pm 0.01 \mathrm{~nm}$ ) (Figure 3f, Supplementary Data Tables S2 and S3, and Figure S7). These crystals are isomorphous to those prepared in the presence of acetone, various alcohols such as 2-propanol [23], geraniol, fenchone, menthone [24], thymol or terpineol [56] and thus correspond to the V7 allomorph [25].

\subsection{Mixtures of crystal types}

Since the three types of morphologies described above have distinct features, the coexistence of V-amylose allomorphs could be unambiguously identified from TEM images (Figure 4) and XRD diagrams (Figure 5). Table 1 summarizes the allomorphic types observed for complexes formed with each fatty acid. A general observation is that all complexing agents could induce more than one crystalline structure. Specifically, PROA (C3) formed V6 I and V7 while all longer-chain fatty acids (C4-C20) promoted the formation of $\mathrm{V} 6_{\mathrm{I}}, \mathrm{V}_{\mathrm{II}}$ and V7. Tables 2-4 detail the results obtained with different solvent compositions, fatty acid concentrations and crystallization temperatures. The relative amount of allomorphs was evaluated from the peak intensities in the XRD profile. TEM images were used to identify different crystal forms, even when one of both forms was in minor amount and the corresponding XRD patterns showed only one allomorph. Selected XRD profiles for different mixtures of allomorphs are shown in Figure 5. Depending on the crystallization conditions, the product contained only one type of crystal or coexisting allomorphs. The two allomorphs of $\mathrm{V}_{\mathrm{PROA}}$ complexes, V6 $6_{\mathrm{I}}$ and V7, always formed simultaneously but the relative amounts could be modified by varying the crystallization temperature. Typically, $\mathrm{V} 6_{\mathrm{I}}$ was favored at higher temperatures. Upon crystallization in water in the presence of $40 \mathrm{vol} \%$ of PROA at $40{ }^{\circ} \mathrm{C}$, V7 was the major form. Keeping similar crystallization mixtures at $50-75{ }^{\circ} \mathrm{C}$ resulted in $\mathrm{V} 6 \mathrm{I}$ as the main allomorph (Table 2, Supplementary Data Figure S8). However, the result was different when the solvent composition and concentration of PROA were changed. By increasing PROA to 50 vol\% or upon crystallization in the presence of $10 \mathrm{vol} \%$ DMSO, V6 I was the major allomorph at all tested temperatures (Tables 2 and 4, Supplementary Data Figure S8). 
Similar results were obtained for $\mathrm{V}_{\mathrm{BUTA}}$ complexes. Higher BUTA concentrations and the presence of DMSO favored the formation of V6I (Tables 2 and 4, Supplementary Data Figure S9). Besides, at $40{ }^{\circ} \mathrm{C}$ and low concentrations of BUTA (5-10 vol\%), amylose crystallized into a mixture of $\mathrm{V} 6_{\text {II }}$ and $V 7$. Despite the fact that $V 6_{\text {II }}$ crystals were recognized in TEM images (Figure 4e), the corresponding reflections were not visible in the XRD profile (Supplementary Data Figure S9), suggesting that the amount of V6 $6_{\text {II }}$ was lower than $5 \%$.

For longer fatty acids (C5-C20), $\mathrm{V} 6$ II crystals were also formed at lower temperatures $\left(40-50{ }^{\circ} \mathrm{C}\right.$ ) than $\mathrm{V6}_{\mathrm{I}}$ complexes (Tables 2-4, Supplementary Data Figures S10 and S11). It must be noted that a successful preparation of $\mathrm{V} 6_{\text {II }}$ with $\mathrm{C} 10-\mathrm{C} 20$ fatty acids required an incubation of the amylose-lipid mixture at $100-110{ }^{\circ} \mathrm{C}$ for $24 \mathrm{~h}$ before cooling down to the crystallization temperature $\left(40-50{ }^{\circ} \mathrm{C}\right)$. Without this incubation period, amorphous and B-type amylose formed as well. Besides, V6 $6_{\text {II }}$ was generally not favored with 10 vol\% DMSO. On the other hand, with C5-C20 fatty acids, V7 crystals only formed in the presence of the appropriate amount of DMSO (2 vol\%) (Table 3). 10 vol\% DMSO favored V6I instead. In addition, for the complexation with PENA (C5), the formation of V7 was preferred to that of $\mathrm{V} 6_{\text {II }}$ at lower fatty acid concentrations and higher temperatures (Table 3, Supplementary Data Figure S10). For C6-C20, the conditions in which V7 was the unique or the main crystallized form were not determined. V7 crystals always formed in minor amount concomitantly with V6 In In these cases, the crystals were always present attached to those of V6I, possibly implying a twinning mechanism (Figure 4c,d). A similar pattern was observed for the coexistence of $V 6_{I}$ and $V 6_{I I}$ (Figure 4a,b) whereas coexisting V6 $6_{I I}$ and V7 crystals seemed to have grown independently (Figure 4e,f).

\section{Discussion}

Our data clearly show that highly crystalline complexes of $\mathrm{V}$-amylose could be prepared with a series of saturated linear fatty acids ( $\mathrm{C} 3$ to $\mathrm{C} 20)$ at temperatures as low as $40{ }^{\circ} \mathrm{C}$, which agrees with the conclusions of Marinopoulou et al. [57] but contradicts other reports that mention that a crystallization at a temperature lower than $60^{\circ} \mathrm{C}$ only yields amorphous complexes [37,58].

However, a successful crystallization requires to mix the fatty acids and amylose solutions at a high temperature $\left(90-100^{\circ} \mathrm{C}\right)$ and, for the $\mathrm{V} 6_{\text {II }}$ allomorph prepared with $\mathrm{C} 10-\mathrm{C} 20$ ligands, to maintain the mixture at this temperature for $24 \mathrm{~h}$ before cooling down to the crystallization temperature. According to Whittam et al. [59], the formation of crystalline V-amylose requires two steps: i) the association of amylose and complexing agent into helical complexes, followed by ii) the formation of crystal by association of the helices under suitable conditions. The 
interaction of fatty acids with amylose in solution at a temperature higher than the crystallization temperature is thus critical to promote the formation of $\mathrm{V}$-amylose single helices.

A salient and unexpected result of our study is that the polymorphism of V-amylose was observed for all tested fatty acids rather than only for PROA, BUTA and HEXA as reported in previous articles (Table 1) [16,35,39]. The observed allomorphs differ by the 6- or 7-fold helical conformation of amylose, packing of helices and location of the guest fatty acids in the unit cells. In $\mathrm{V}_{\text {I }}$ crystals, the helices are packed into a compact hexagonal unit cell and, therefore, the guest molecules can only be located inside the helices [36]. In contrast, V6 $6_{\text {II }}$ and V7 are less compact structures where the guest and water molecules can be located inside and between the helices (Figure 6) [17,25].

We have shown that all tested fatty acids could induce the formation of both 6- and 7-fold helices whereas earlier works reported that the amylose conformation depended on the chain length of complexing agent $[16,60]$. In particular, the occurrence of V7 with long-chain fatty acids C6-C20 has never been reported before (Table 1). If the cross-sectional diameter of the linear fatty acids $(c a .0 .30 \mathrm{~nm})$ is considered, V6 structures are expected rather than V7. V7 is usually obtained with bulkier complexing agents such as branched alcohols or monoterpenes whose cross-sectional diameter is $0.45-0.60 \mathrm{~nm}[11,16,22,24,39,60]$. In this context, Shogren et al. [32] proposed that the formation of 7-fold helices with fatty acids was due to the complexation of amylose with fatty acid "dimers", the association of which would be promoted by hydrophobic interactions between the alkyl moieties [61]. However, our results showed that V7 was more favorable with water-miscible fatty acids (C3 and $\mathrm{C} 4)$ than with the poorly soluble ones. Moreover, several complexes formed at high temperature $\left(90^{\circ} \mathrm{C}\right)$ at which the existence of fatty acid "dimers" in solution was unlikely. Therefore, the 7-fold helical conformation is more likely controlled by a specific interaction between fatty acids and amylose rather than by the molecular dimension of the guest molecule. As proposed by Takeo et al. [16], the inclusion of the polar head (i.e. the carboxyl group) of the fatty acid in the amylose helix could be responsible for its enlargement to the V7 conformation.

In contrast, straight-chain molecules bearing a different functional group such as aliphatic $n$ alcohols and aldehydes have been reported to only induce the formation of 6-fold helices $[35,62]$. Besides, previous numerical simulations and NMR data concluded that the linear alkyl moiety was included inside the 6-fold helix while the polar head remained outside [14,63-65]. In addition, the hypothesis that the inclusion of carboxyl group controls the helical conformation somehow agrees with the fact that V7 is more preferred with shorter fatty acids (C3-C5). In the case of C6-C20, V7 crystals always formed in minor amount concomitantly with V6. It is 
possible that with a longer chain length, the influence of the linear aliphatic chain gets predominant over that of the carboxyl group in determining the size of helix and thus would induce mainly 6-fold helical complexes [16]. Expanding from the modeling work of Godet et al. [14], further simulations must be carried out to elucidate the role of the carboxyl group and its interaction with amylose in the determination of its helical conformation. Moreover, the crystallization of amylose with other homologous series of aliphatic linear guests with different functional groups (straight-chain alcohols, aldehydes, esters, ketones, etc.) should be systematically investigated to see whether the formation of the V7 allomorph can be induced.

The present study showed that a systematic screening of a variety of crystallization conditions was necessary to explore the polymorphism of $\mathrm{V}_{\text {fatty acid }}$ complexes. Our results revealed that with a given fatty acid, different allomorphs could crystallize, alone or in mixtures, depending on the conditions (Tables 2-4). A similar behavior has previously been reported for many polymorphic systems, as reviewed by Bernstein et al. [66]. The phenomenon has been explained by the fact that so-called occurrence domains, defined by sets of conditions at which specific allomorphs crystallize, could be independent or overlap. When the occurrence domain is unique, only one form is obtained, which is usually the most thermodynamically stable. In contrast, in regions where the domains overlap, two or more forms would crystallize under identical conditions. These concomitant allomorphs are energetically close and their relative amount is mainly governed by kinetic stability $[66,67]$.

Since we have only characterized the morphology and structure of the final products, the precise chronology of crystallization events was lost. The possibility that the amylose chains form nuclei and crystallize under conditions that depend on their length (so-called fractionated crystallization) or on the temperature (during cooling) cannot be ruled out. One allomorph would crystallize after the other and the allomorph formed first may even act as a seed for nucleation and epitaxial growth of the second one. As illustrated by Figures $\mathbf{4 a}$ and $\mathbf{4 b}$, rectangular V6 II and hexagonal $\mathrm{V}_{\mathrm{I}}$ crystals are often associated, exhibiting specific orientation relationships that were not precisely analyzed in the present study. However, since the images are projections of the crystal assemblies, one cannot clearly identify the crystallization sequence of each allomorph. In the case of coexisting V6 $\mathrm{I}$ and $\mathrm{V} 7$ crystals, the latter ones are mostly observed as outgrowths of the former (Figure 4d), suggesting that they formed the last. V6 $6_{\text {II }}$ and V7 crystals did not appear to be associated but rather independent from one another (Figures $4 \mathbf{e}$ and $\mathbf{4 f}$ ).

In our study, three parameters were shown to play important roles to regulate the complexforming ability and molecular packing, namely the fatty acid concentration, the temperature, and the solvent composition. It appears that the compact V6 Itructure was favored at higher 
concentrations of fatty acid and DMSO (10 vol\%), and a higher temperature $\left(60-90^{\circ} \mathrm{C}\right)$. However, milder conditions of these parameters result in the formation of the less dense structure that contains inter-helical cavities (V6 II and V7 - Figure 6b,c). Similar observations on the effect of complexing agent concentration were reported earlier for PROA and BUTA as well as 2-propanol and acetone $[16,35,60]$. A common feature of these molecules is that they are water-miscible. To ensure the crystallization of V-amylose, they must be used at a higher concentration (5-50 vol\%) than that used for insoluble complexing agents, i.e. long-chain fatty acids $(<0.1 \mathrm{vol} \%)$.

In addition to promoting the interaction with amylose, high concentrations of complexing agents may induce a significant dehydration on the polymer and thus favor the formation of the more compact V6 I structure [16,35]. Moreover, previous works have shown that V6 II and V7 crystals were stable in an aqueous environment whereas drying or washing with methanol resulted in the conversion into the more compact $\mathrm{V} 6_{\text {I }}$ structure $[17,23]$. In the case of BUTA, V6 $6_{\text {II }}$ was more sensitive to dehydration than $\mathrm{V} 7$, the former appearing only with a BUTA concentration $\leq 10 \mathrm{vol} \%$ while the later was formed at higher concentration. This also explains why V6 obtained with PROA for which at least $30 \mathrm{vol} \%$ was required to form the complexes.

The impact of DMSO on the formation of specific allomorphs has been clearly highlighted. This molecule is a good solvent of amylose but also of fatty acids which increases the concentration of weakly soluble fatty acids and therefore, their availability for complexation. Helbert [35] also observed different allomorphs for complexes prepared with $n$-butanol that exhibited a $\mathrm{V}_{\text {II }}$ structure when crystallized in water and $\mathrm{V} 6_{\mathrm{I}}$ in DMSO:water mixtures. It must also be noted that DMSO can form crystalline complexes with amylose [68,69]. While Simpson et al. [70] mentioned the occurrence of two allomorphs based on 6- and 7-fold amylose helices, Winter and Sarko [18] described the $\mathrm{V}_{\mathrm{DMSO}}$ unit cell as pseudo-tetragonal and containing antiparallel 6-fold helices, with DMSO molecules located inside and between helices. However, this complex was only formed under anhydrous conditions by casting amylose / DMSO solutions and letting them to dry in a vacuum oven. Nevertheless, this shows that in specific conditions, DMSO no longer acts as a solvent of amylose but rather like a complexing agent that specifically interacts with amylose chains to form helical inclusion compounds.

The most remarkable effect of DMSO was its crucial role in the formation of V7. Our results showed that the complexes with C5-C20 fatty acids exhibited a V7 structure only if DMSO was present. A significant role of DMSO on the conformation of amylose has been suggested by other authors [35,69,70-72]. DMSO may induce specific conformations for both amylose and fatty acids, although, so far, the nature of the interactions remains unknown and no evidence were produced regarding the presence of DMSO in the crystal structure of $\mathrm{V}_{\text {fatty acids }}$ complexes. 


\section{Conclusion}

The crystallization of amylose with a series of homologous saturated straight-chain fatty acids confirmed the polymorphism of $\mathrm{V}_{\text {fatty acid }}$ complexes hinted at by previous authors. The helical conformation of amylose was independent of the fatty acid chain length. By adjusting the crystallization conditions, each fatty acid of the series (C3 to $\mathrm{C} 20)$ induced both 6- and 7-fold helices that packed into different unit cells. Propanoic acid yielded V6 $6_{\text {I }}$ or V7 while the fatty acids having 4 to 20 carbons induced the formation of crystals with the V6 $6_{I}, V 6_{\text {II }}$ or V7 structure. The results highlight the important role of fatty acid concentration, temperature and solvent composition on the crystal structure of the complexes. Depending on these parameters, a unique allomorph or mixtures of several were obtained. Some trends could be identified: i) a higher concentration of fatty acid and DMSO and a higher temperature promoted the formation of the

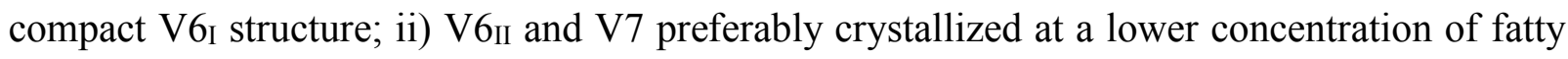
acids and DMSO and at lower temperatures; iii) with C5-C20 fatty acids, V7 was only obtained in the presence of DMSO. Further studies on the stoichiometry, location of the guest fatty acid molecules and their interaction with amylose are in progress. Conducting similar studies with homologous series of other molecules, such as linear alcohols, aldehydes, ketones or esters should be undertaken since the amylose polymorphism has not been systematically investigated with these compounds.

\section{Acknowledgement}

We thank LabEx Arcane (grant agreement \#ANR-11-LABX-0003-01) for funding the PhD thesis of C.A.K.L, the NanoBio-ICMG platform (UAR 2607, Grenoble) for granting access to the Electron Microscopy facility, Christine Lancelon-Pin (CERMAV) for her help with sample preparation, the Glyco@Alps program (Investissements d'Avenir grant agreement \#ANR-15IDEX-02), and Henri Chanzy for stimulating discussions and critical reading of the manuscript.

\section{References}

[1] I. Hanashiro, Fine structure of amylose, In "Starch: Metabolism and Structure", Y. Nakamura ed., 2015, Springer, pp. 41-60.

[2] D. Popov, A. Buléon, M. Burghammer, H. Chanzy, N. Montesanti, J.-L. Putaux, G. Potocki-Véronèse, C. Riekel, Crystal structure of A-amylose: A revisit from 
synchrotron microdiffraction analysis of single crystals, Macromolecules 42 (2009) $1167-1174$.

[3] A. Imberty, S. Pérez, A revisit to the three-dimensional structure of B-type starch, Biopolymers 27 (1988) 1205-1221.

[4] R.S. Bear, Complex formation between starch and organic molecules, J. Am. Chem. Soc. 66 (1944) 2122-2123.

[5] F. Mikus, R. Hixon, R. Rundle, The complexes of fatty acids with amylose, J. Am. Chem. Soc. 68 (1946) 1115-1123.

[6] T.L. Bluhm, P. Zugenmaier, Detailed structure of the Vh-amylose-iodine complex: a linear polyiodine chain, Carbohydr. Res. 89 (1981) 1-10.

[7] P. Tomasik, C.H. Schilling, Complexes of starch with inorganic guests, Adv. Carbohydr. Chem. Biochem. 53 (1998) 263-343.

[8] P. Tomasik, C.H. Schilling, Complexes of starch with organic guests, Adv. Carbohydr. Chem. Biochem. 53 (1998) 346-426.

[9] J.A. Putseys, L. Lamberts, J.A. Delcour, Amylose-inclusion complexes: formation, identity and physico-chemical properties, J. Cereal Sci. 51 (2010) 238-247.

[10] W.C. Obiro, S. Sinha Ray, M.N. Emmambux, V-amylose structural characteristics, methods of preparation, significance, and potential applications, Food Rev. Int. 28 (2012) $412-438$.

[11] Y.-H. Yamashita, J. Ryugo, K. Monobe, An electron microscopy study on crystals of amylose V complexes, J. Electron Microsc. 22 (1973) 19-26.

[12] D. Lourdin, J.-L. Putaux, G. Potocki-Véronèse, C. Chevigny, A. Roland-Sabaté, A. Buléon, Crystalline structure in starch, In "Starch - Metabolism and Structure", Y. Nakamura ed., Springer Japan, 2015, pp. 61-90.

[13] J. Brisson, H. Chanzy, W.T. Winter, The crystal and molecular structure of $\mathrm{V}_{\mathrm{H}}$ amylose by electron diffraction analysis, Int. J. Biol. Macromol. 13 (1991) 31-39.

[14] M.C. Godet, V. Tran, M.-M. Delage, A. Buléon, Molecular modelling of the specific interactions involved in the amylose complexation by fatty acids, Int. J. Biol. Macromol. 15 (1993) 11-16.

[15] G. Rappenecker, P. Zugenmaier, Detailed refinement of the crystal structure of $\mathrm{V}_{\mathrm{h}^{-}}$ amylose, Carbohydr. Res. 89 (1981) 11-19.

[16] K. Takeo, A. Tokumura, T. Kuge, Complexes of starch and its related materials with organic compounds. Part X. X-Ray diffraction of amylose-fatty acid complexes, Die Stärke 25 (1973) 357-362. 
[17] W. Helbert, H. Chanzy, Single crystals of V-amylose complexed with n-butanol or npentanol: structural features and properties, Int. J. Biol. Macromol. 16 (1994) 207-213.

[18] W.T. Winter, A. Sarko, Crystal and molecular structure of the amylose-DMSO complex, Biopolymers 13 (1974) 1461-1482.

[19] T.D. Simpson, X-Ray diffraction of ethylenediamine-amylose complex, Biopolymers 9 (1970) 1039-1047.

[20] S.H.D. Hulleman, W. Helbert, H. Chanzy, Single crystals of V amylose complexed with glycerol, Int. J. Biol. Macromol. 18 (1996) 115-122.

[21] B. Zaslow, Characterization of a second helical amylose modification, Biopolymers 1 (1963) 165-169.

[22] Y. Yamashita, N. Hirai, Single crystals of amylose V complexes. II. Crystals with $7_{1}$ helical configuration, J. Polym. Sci.Part A-2: Polym. Phys. 4 (1966) 161-171.

[23] A. Buléon, M.M. Delage, J. Brisson, H. Chanzy, Single crystals of V amylose complexed with isopropanol and acetone, Int. J. Biol. Macromol. 12 (1990) 25-33.

[24] J. Nuessli, J.-L. Putaux, P. Le Bail, A. Buléon, Crystal structure of amylose complexes with small ligands. Int. J. Biol. Macromol. 33 (2003) 227-234.

[25] Y. Nishiyama, K. Mazeau, M. Morin, M.B. Cardoso, H. Chanzy, J.-L. Putaux, Molecular and crystal structure of 7-fold V-amylose complexed with 2-propanol, Macromolecules 43 (2010) 8628-8636.

[26] M.B. Cardoso, J.-L. Putaux, Y. Nishiyama, W. Helbert, M. Hÿtch, N.P. Silveira, H. Chanzy, Single crystals of V-amylose complexed with $\alpha$-naphthol, Biomacromolecules 8 (2007) 1319-1326.

[27] W.R. Morrison, Lipids in cereal starches: A review, J. Cereal Sci. 8 (1988) 1-15.

[28] T.J. Schoch, C.B. Williams, Adsorption of fatty acid by the linear component of corn starch, J. Am. Chem. Soc. 66 (1944) 1232-1233.

[29] T. Davies, D.C. Miller, A.A. Procter, Inclusion complexes of free fatty acids with amylose, Starch/Stärke 32 (1980) 149-158.

[30] Z. Cao, A.J.J. Woortman, P. Rudolf, K. Loos, Facile synthesis and structural characterization of amylose-fatty acid inclusion complexes, Macromol. Biosci. 15 (2015) 691-697.

[31] G.F. Fanta, R.L. Shogren, J.H. Salch, Steam jet cooking of high-amylose starch-fatty acid mixtures. An investigation of complex formation, Carbohydr. Polym. 38 (1999) 1-6. 
[32] R.L. Shogren, G.F. Fanta, F.C. Felker, X-ray diffraction study of crystal transformations in spherulitic amylose/lipid complexes from jet-cooked starch, Carbohydr. Polym. 64 (2006) 444-451.

[33] U. Lesmes, S.H. Cohen, Y. Shener, E. Shimoni, Effects of long chain fatty acid unsaturation on the structure and controlled release properties of amylose complexes, Food Hydrocoll. 23 (2009) 667-675.

[34] A.E. Panyoo, M.N. Emmambux, Amylose-lipid complex production and potential health benefits: A mini-review, Starch/Stärke 69 (2017) 1600203.

[35] W. Helbert, Données sur la structure du grain d'amidon et des produits de recristallisation de l'amylose, Doctoral dissertation, 1994, Université Joseph Fourier, France

[36] M.C. Godet, H. Bizot, A. Buléon, Crystallization of amylose-fatty acid complexes prepared with different amylose chain lengths, Carbohydr. Polym. 27 (1995) 47-52.

[37] J. Karkalas, S. Ma, W.R. Morrison, R.A. Pethrick, Some factors determining the thermal properties of amylose inclusion complexes with fatty acids, Carbohydr. Res. 268 (1995) $233-247$.

[38] F. Tufvesson, M. Wahlgren, A.-C. Eliasson, Formation of amylose-lipid complexes and effects of temperature treatment. Part 2. Fatty acids, Starch/Stärke 55 (2003) 138-149.

[39] B. Biais, P. Le Bail, P. Robert, B. Pontoire, A. Buléon, Structural and stoichiometric studies of complexes between aroma compounds and amylose. Polymorphic transitions and quantification in amorphous and crystalline areas, Carbohydr. Polym. 66 (2006) $306-315$.

[40] A. Marinopoulou, E.P. Kalogianni, S.N. Raphaelides, Amylose-fatty acid inclusion complexes as examined by interfacial tension measurements, Colloid Surface B 137 (2016) 133-137.

[41] S. Ozcan, D.S. Jackson, The impact of thermal events on amylose-fatty acid complexes, Starch/Stärke 54 (2002) 593-602.

[42] S. Raphaelides, J. Karkalas, Thermal dissociation of amylose-fatty acid complexes, Carbohydr. Res. 172 (1988) 65-82.

[43] S. Raphaelides, Rheological studies of starch-fatty acid gels, Food Hydrocoll. 7 (1993) 479-495.

[44] J. Singh, N. Singh, S. Saxena, Effect of fatty acids on the rheological properties of corn and potato starch, J. Food Eng. 52 (2002) 9-16. 
[45] G.G. Gelders, J.P. Duyck, H. Goesaert, J.A. Delcour, Enzyme and acid resistance of amylose-lipid complexes differing in amylose chain length, lipid and complexation temperature, Carbohydr. Polym. 60 (2005) 379-389.

[46] J. Holm, I. Björck, S. Ostrowska, A.C. Eliasson, N.G. Asp, K. Larsson, I. Lundquist, Digestibility of amylose-lipid complexes in-vitro and in-vivo, Starch/Stärke 35 (1983) 294-297.

[47] A. Marinopoulou, E. Papastergiadis, S.N. Raphaelides, M.G. Kontominas, Morphological characteristics, oxidative stability and enzymic hydrolysis of amylosefatty acid complexes, Carbohydr. Polym. 141 (2016) 106-115.

[48] G.G. Gelders, H. Goesaert, J.A. Delcour, Amylose-lipid complexes as controlled lipid release agents during starch gelatinization and pasting, J. Agr. Food Chem. 54 (2006) $1493-1499$.

[49] W.R. Morrison, A.M. Coventry, Solvent extraction of fatty acids from amylose inclusion complexes, Starch/Stärke 41 (1989) 24-27.

[50] S. Bhatnagar, M.A. Hanna, Starch-stearic acid complex development within single and twin screw extruders, J. Food Sci. 61 (1996) 778-782.

[51] J. Laugier, B. Bochu, LMGP-Suite: Suite of programs for the interpretation of X-ray experiments, http://www.cristal.org/DU-SDPD/nexus/ccp14/web/tutorial/lmgp/

[52] P. Le Bail, C. Rondeau, A. Buléon, Structural investigation of amylose complexes with small ligands: Helical conformation, crystalline structure and thermostability, Int. J. Biol. Macromol. 35 (2005) 1-7.

[53] R. St. J. Manley, Chain folding in amylose crystals, J. Polym. Sci. A 2 (1964) 45034515.

[54] F.P. Booy, H. Chanzy, A. Sarko, Electron diffraction study of single crystals of amylose complexed with n-butanol, Biopolymers 18 (1979) 2261-2266.

[55] J.D.H. Donnay, Rules for the conventional orientation of crystals, Am. Mineral. 28 (1943) 313-328.

[56] J.-L. Putaux, Y. Nishiyama, K. Mazeau, M. Morin, M.B. Cardoso, H. Chanzy, Helical conformation in crystalline inclusion complexes of $\mathrm{V}$-amylose: A historical perspective, Macromol. Symp. 303 (2011) 1-9.

[57] A. Marinopoulou, E. Papastergiadis, S.N. Raphaelides, M.G. Kontominas, Structural characterization and thermal properties of amylose-fatty acid complexes prepared at different temperatures, Food Hydrocoll. 58 (2016) 224-234. 
[58] C.G. Biliaderis, G. Galloway, Crystallization behavior of amylose-V complexes: Structure-property relationships, Carbohydr. Res. 189 (1989) 31-48.

[59] M.A. Whittam, P.D. Orford, S.G. Ring, S.A. Clark, M. L. Parker, P. Cairns, M. J. Miles, Aqueous dissolution of crystalline and amorphous amylose-alcohol complexes, Int. J. Biol. Macromol. 11 (1989) 339-344.

[60] K. Takeo, T. Kuge, Complexes of starchy materials with organic compounds. Part VI. X-ray diffraction of amylose- $n$-aliphatic ketone complexes, Agr. Biol. Chem. 35 (1971) $537-542$.

[61] P. Mukerjee, Dimerization of long-chain fatty acids in aqueous solutions and the hydrophobic properties of the acids, J. Phys. Chem. 69 (1965) 2821-2827.

[62] B. Conde-Petit, F. Escher, J. Nuessli, Structural features of starch-flavor complexation in food model systems, Trends Food Sci. Tech. 17 (2006) 227-235.

[63] J. Kawada, R.H. Marchessault, Solid state NMR and X-ray studies on amylose complexes with small organic molecules, Starch 56 (2004) 13-19.

[64] P. Lebail, A. Buléon, D. Shiftan, R.H. Marchessault, Mobility of lipid in complexes of amylose-fatty acids by deuterium and ${ }^{13} \mathrm{C}$ solid state NMR, Carbohydr. Polym. 43 (2000) $317-326$.

[65] C.E. Snape, W.R. Morrison, M.M. Maroto-Valer, J. Karkalas, R.A. Pethrick, Solid state ${ }^{13} \mathrm{C}$ NMR investigation of lipid ligands in V-amylose inclusion complexes, Carbohydr. Polym. 36 (1998) 225-237.

[66] J. Bernstein, R.J. Davey, J.-O. Henck, Concomitant polymorphs, Angew. Chem. Int. Edit. 38 (1999) 3440-3461.

[67] D.-K. Bučar, R.W. Lancaster, J. Bernstein. Disappearing polymorphs revisited, Angew. Chem. Int. Edit. 54 (2015) 6972-6993.

[68] A.D. French, H.F. Zobel, X-ray diffraction of oriented amylose fibers. I. Amylose dimethyl sulfoxide complex, Biopolymers 5 (1967), 457-464.

[69] F.J. Germino, R.M. Valletta, Amylose V complexes from dimethyl sulfoxide solutions, J. Polym. Sci. A 2 (1964) 4757-4763.

[70] T.D. Simpson, F.R. Dintzis, N.W. Taylor, A V7 conformation of dimethyl sulfoxideamylose complex, Biopolymers 11 (1972) 2591-2600.

[71] J.-L. Jane, J.F. Robyt, D.-H. Huang, 13C-NMR study of the conformation of helical complexes of amylodextrin and of amylose in solution, Carbohydr. Res. 140 (1985) 21-35.

[72] N.W.H. Cheetham, L. Tao, Amylose conformational transitions in binary DMSO/water mixtures, Carbohydr. Polym. 35 (1998) 287-295. 


\section{Tables and figures}

Table 1. Summary of the allomorphs observed for the crystalline complexes of V-amylose with linear fatty acids as a function of the number of carbon atoms in the fatty chain and comparison with previous works.

\begin{tabular}{ccc}
\hline Fatty acid & Previous works & This work \\
\hline PROA (C3) & $\mathrm{V}_{\mathrm{I}}^{\mathrm{a}}{ }^{\mathrm{a}, \mathrm{b}}, \mathrm{V} 7^{\mathrm{a}, \mathrm{b}}$ & $\mathrm{V} 6_{\mathrm{I}}, \mathrm{V} 7$ \\
BUTA (C4) & $\mathrm{V}_{\mathrm{I}}^{\mathrm{a}, \mathrm{b}}, \mathrm{V} 7^{\mathrm{b}}$ & $\mathrm{V} 6_{\mathrm{I}}, \mathrm{V} 6_{\mathrm{II}}, \mathrm{V7}$ \\
PENA (C5) & $\mathrm{V} 7^{\mathrm{a}, \mathrm{b}}$ & $\mathrm{V} 6_{\mathrm{I}}, \mathrm{V} 6_{\mathrm{II}}, \mathrm{V} 7$ \\
HEXA (C6) & $\mathrm{V}_{\mathrm{I}}^{\mathrm{a}}, \mathrm{V} 6_{\mathrm{II}}^{\mathrm{c}}$ & $\mathrm{V} 6_{\mathrm{I}}, \mathrm{V} 6_{\mathrm{II}}, \mathrm{V7}$ \\
OCTA, DECA, DODA, TEDA, & & \\
HEDA, OCDA, ICOA* & $\mathrm{V}_{\mathrm{I}}^{\mathrm{a}, \mathrm{b}}$ & $\mathrm{V} 6_{\mathrm{I}}, \mathrm{V} 6_{\mathrm{II}}, \mathrm{V7}$ \\
$(\mathrm{C} 8-\mathrm{C} 20)$ & & \\
\hline
\end{tabular}

${ }^{a}$ Takeo et al. [16], ${ }^{b}$ Helbert [35], ${ }^{c}$ Biais et al. [39]

* The crystal type of VICOA has not previously been reported. 
Table 2. Allomorphic type of $\mathrm{V}_{\text {fatty acid }}$ crystals formed in water at different fatty acid concentrations $\left(\mathrm{C}_{\text {fatty acid }}\right)$ and temperatures. The amylose solutions and fatty acids were mixed at $90{ }^{\circ} \mathrm{C}$, then kept at a given crystallization temperature, or allowed to slowly cool down to room temperature in a Dewar container. For mixtures, the major and minor allomorphs are indicated.

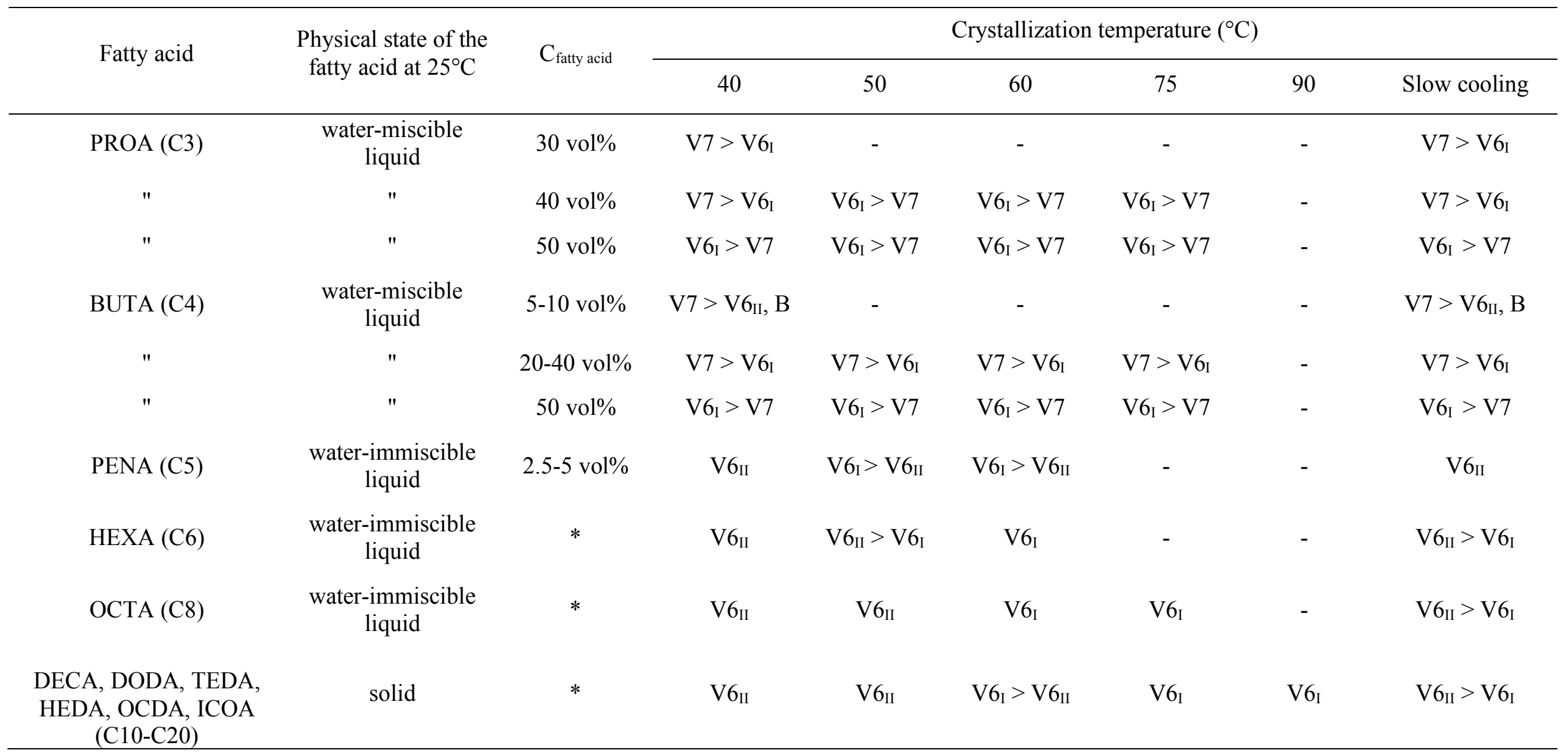

*: the fatty acid was used at saturation

-: no precipitation 
Table 3. Allomorphic type of $\mathrm{V}_{\text {fatty acid }}$ crystals formed in the presence of $2 \mathrm{vol} \% \mathrm{DMSO}$ at different fatty acid concentrations $\left(\mathrm{C}_{\text {fatty acid }}\right)$ and temperatures. The amylose solutions and fatty acids were mixed at $90{ }^{\circ} \mathrm{C}$, then kept at a given crystallization temperature. For mixtures, the major and minor allomorphs are indicated.

\begin{tabular}{|c|c|c|c|c|c|}
\hline \multirow{2}{*}{ Fatty acid } & \multirow{2}{*}{$\mathrm{C}_{\text {fatty acid }}$} & \multicolumn{4}{|c|}{ Crystallization temperature $\left({ }^{\circ} \mathrm{C}\right)$} \\
\hline & & 40 & 60 & 75 & 90 \\
\hline PROA (C3) & n. t. & n. t. & n. t. & n. t. & n. t. \\
\hline BUTA (C4) & n. t. & n. t. & n. t. & n. t. & n. t. \\
\hline PENA (C5) & $2.5 \mathrm{vol} \%$ & V7 & V7 & - & - \\
\hline$"$ & $3 \mathrm{vol} \%$ & $\mathrm{~V} 7>\mathrm{V} 6_{\mathrm{II}}$ & V7 & - & - \\
\hline$"$ & $4-5$ vol $\%$ & $\mathrm{V6}_{\text {II }}$ & V7 & - & - \\
\hline HEXA (C6) & $*$ & $\mathrm{~V} 6_{\text {II }}$ & $\mathrm{V} 6_{\mathrm{I}}>\mathrm{V} 7$ & $\mathrm{~V} 6_{\mathrm{I}}>\mathrm{V} 7$ & - \\
\hline OCTA $(\mathrm{C} 8)$ & n. t. & n. t. & n. t. & n. t. & n. t. \\
\hline $\begin{array}{c}\text { DECA, DODA, TEDA, } \\
\text { HEDA, OCDA, ICOA } \\
(\mathrm{C} 10-\mathrm{C} 20)\end{array}$ & $*$ & n. t. & n. t. & $\mathrm{V6} 6_{\mathrm{I}}>\mathrm{V7}$ & $\mathrm{V6} 6_{\mathrm{I}}>\mathrm{V} 7$ \\
\hline
\end{tabular}

*: the fatty acid was used at saturation

- : no precipitate was observed

n. t.: not tested 
Table 4. Allomorphic type of $\mathrm{V}_{\text {fatty }}$ acid crystals formed in the presence of $10 \mathrm{vol} \% \mathrm{DMSO}$ at different fatty acid concentrations $\left(\mathrm{C}_{\text {fatty }}\right.$ acid) and temperatures. The amylose solutions and fatty acids were mixed at $90{ }^{\circ} \mathrm{C}$, then kept at a given crystallization temperature, or allowed to slowly cool down to room temperature in a Dewar container. For mixtures, the major and minor allomorphs are indicated.

\begin{tabular}{|c|c|c|c|c|c|c|c|}
\hline \multirow{2}{*}{ Fatty acid } & \multirow{2}{*}{$\mathrm{C}_{\text {fatty acid }}$} & \multicolumn{6}{|c|}{ Crystallization temperature $\left({ }^{\circ} \mathrm{C}\right)$} \\
\hline & & 40 & 50 & 60 & 75 & 90 & Slow cooling \\
\hline PROA (C3) & 30 vol $\%$ & - & - & - & - & - & - \\
\hline$"$ & $40-50$ vol $\%$ & $\mathrm{~V} 6_{\mathrm{I}}>\mathrm{V} 7$ & $\mathrm{~V}_{\mathrm{I}}>\mathrm{V} 7$ & $\mathrm{~V} 6_{\mathrm{I}}>\mathrm{V} 7$ & $\mathrm{~V} 6_{\mathrm{I}}>\mathrm{V} 7$ & - & $\mathrm{V} 6_{\mathrm{I}}>\mathrm{V} 7$ \\
\hline BUTA (C4) & $5-10$ vol\% & $\mathrm{V7}>\mathrm{V} 6_{\mathrm{II}}, \mathrm{B}$ & - & - & - & - & $\mathrm{V} 7>\mathrm{V} 6_{\text {III }}, \mathrm{B}$ \\
\hline$"$ & $20-30$ vol $\%$ & $\mathrm{~V} 7>\mathrm{V} 6_{\mathrm{I}}$ & $\mathrm{V} 7>\mathrm{V} 6_{\mathrm{I}}$ & $\mathrm{V} 7>\mathrm{V} 6_{\mathrm{I}}$ & $\mathrm{V} 7>\mathrm{V} 6_{\mathrm{I}}$ & - & $\mathrm{V} 7>\mathrm{V} 6_{\mathrm{I}}$ \\
\hline " & $40-50$ vol $\%$ & $\mathrm{~V} 6_{\mathrm{I}}>\mathrm{V} 7$ & $\mathrm{~V} 6_{\mathrm{I}}>\mathrm{V} 7$ & $\mathrm{~V} 6_{\mathrm{I}}>\mathrm{V} 7$ & $\mathrm{~V} 6_{\mathrm{I}}>\mathrm{V} 7$ & - & $\mathrm{V} 6_{\mathrm{I}}>\mathrm{V} 7$ \\
\hline PENA (C5) & $2.5 \mathrm{vol} \%$ & $\mathrm{~V} 7>\mathrm{V}_{\mathrm{II}}$ & $\mathrm{V7}>\mathrm{V6} 6_{\mathrm{I}}, \mathrm{V} 6_{\mathrm{II}}$ & - & - & - & n. t. \\
\hline$"$ & 5 vol $\%$ & $\mathrm{~V}_{\mathrm{II}}>\mathrm{V} 7$ & $\mathrm{~V} 6_{\mathrm{II}}>\mathrm{V} 6_{\mathrm{I}}, \mathrm{V} 7$ & $\mathrm{~V} 6_{\mathrm{I}}>\mathrm{V} 7$ & - & - & $\mathrm{V} 6_{\mathrm{II}}>\mathrm{V} 6_{\mathrm{I}}$ \\
\hline $\operatorname{HEXA}(\mathrm{C} 6)$ & $*$ & $\mathrm{~V} 6_{\mathrm{I}}>\mathrm{V} 6_{\mathrm{II}}$ & $\mathrm{V} 6_{\mathrm{I}}>\mathrm{V} 6_{\mathrm{II}}$ & $\mathrm{V} 6_{\mathrm{I}}>\mathrm{V} 7$ & $\mathrm{~V} 6_{\mathrm{I}}>\mathrm{V} 7$ & - & $\mathrm{V} 6_{\mathrm{I}}>\mathrm{V} 6_{\mathrm{II}}$ \\
\hline OCTA (C8) & $*$ & $\mathrm{~V} 6_{\mathrm{I}}>\mathrm{V} 6_{\text {II }}$ & V6 $6_{I}$ & $V 6_{I}$ & $\mathrm{~V} 6_{\mathrm{I}}>\mathrm{V} 7$ & - & $\mathrm{V} 6_{\mathrm{I}}>\mathrm{V} 6_{\mathrm{II}}$ \\
\hline DECA (C10), DODA (C12) & $*$ & $V 6_{I}$ & $V 6_{I}$ & $\mathrm{~V} 6_{\mathrm{I}}$ & $\mathrm{V} 6_{\mathrm{I}}>\mathrm{V} 7$ & $\mathrm{~V} 6_{\mathrm{I}}>\mathrm{V} 7$ & $\mathrm{~V} 6_{\mathrm{I}}>\mathrm{V} 7$ \\
\hline $\begin{array}{l}\text { TEDA, HEDA, OCDA, } \\
\text { ICOA (C14-C20) }\end{array}$ & $*$ & $\mathrm{~V} 6_{\mathrm{I}}$ & $\mathrm{V} 6_{\mathrm{I}}$ & $\mathrm{V} 6_{\mathrm{I}}$ & $\mathrm{V} 6_{\mathrm{I}}$ & $\mathrm{V} 6_{\mathrm{I}}>\mathrm{V} 7$ & $\mathrm{~V} 6_{\mathrm{I}}>\mathrm{V} 7$ \\
\hline
\end{tabular}

*: the fatty acid was used at saturation

-: no precipitate was observed

n. t.: not tested 


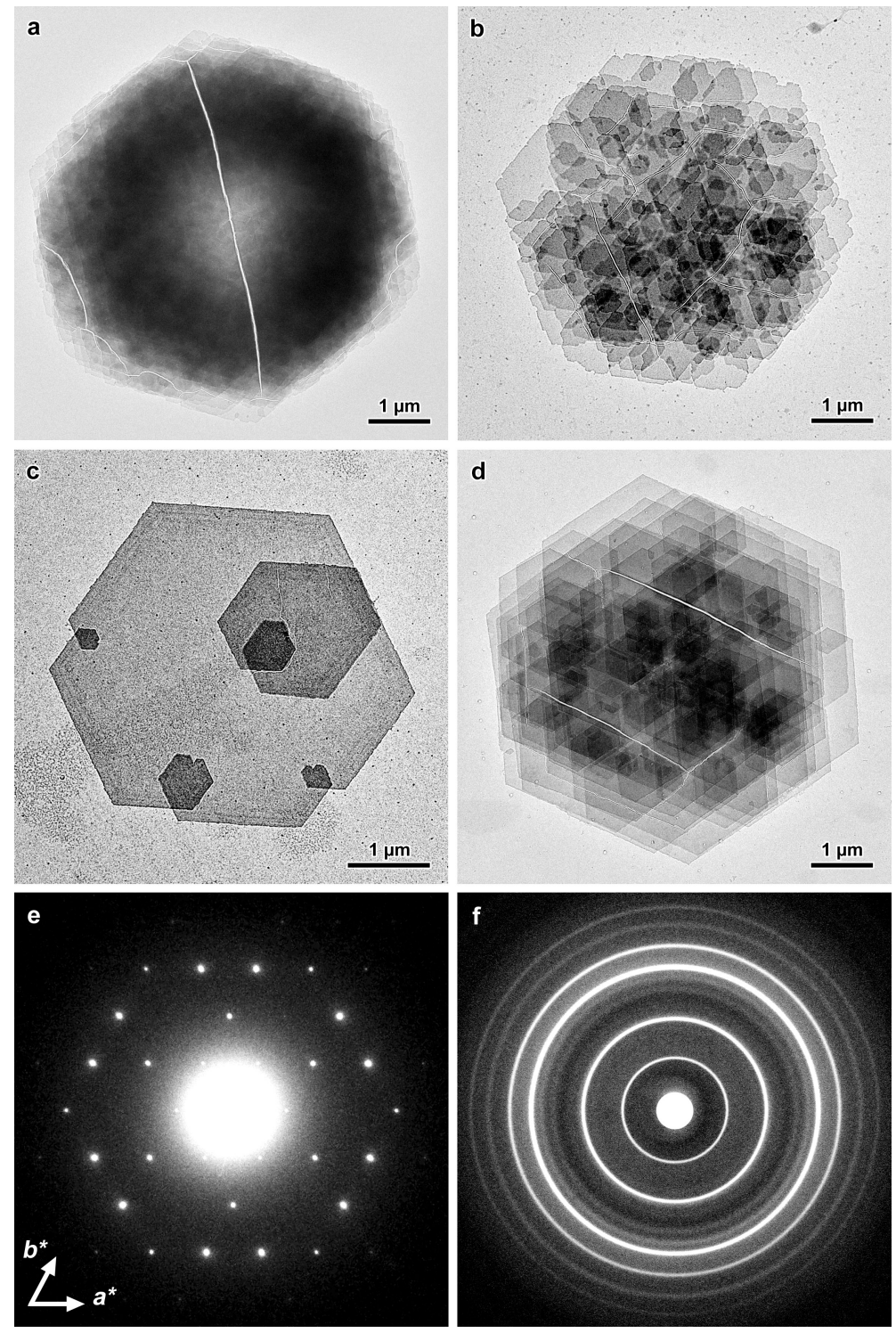

Figure 1. The V6I structure: a-d) TEM images of crystals of V-amylose crystallized with OCTA (a), DODA (b) and TEDA (c,d); e) base-plane ED recorded at low temperature from frozenhydrated $V_{\text {TEDA }}$ crystals; f) powder XRD diagram recorded from $V_{\text {TEDA }}$ crystals equilibrated at $95 \%$ RH. 


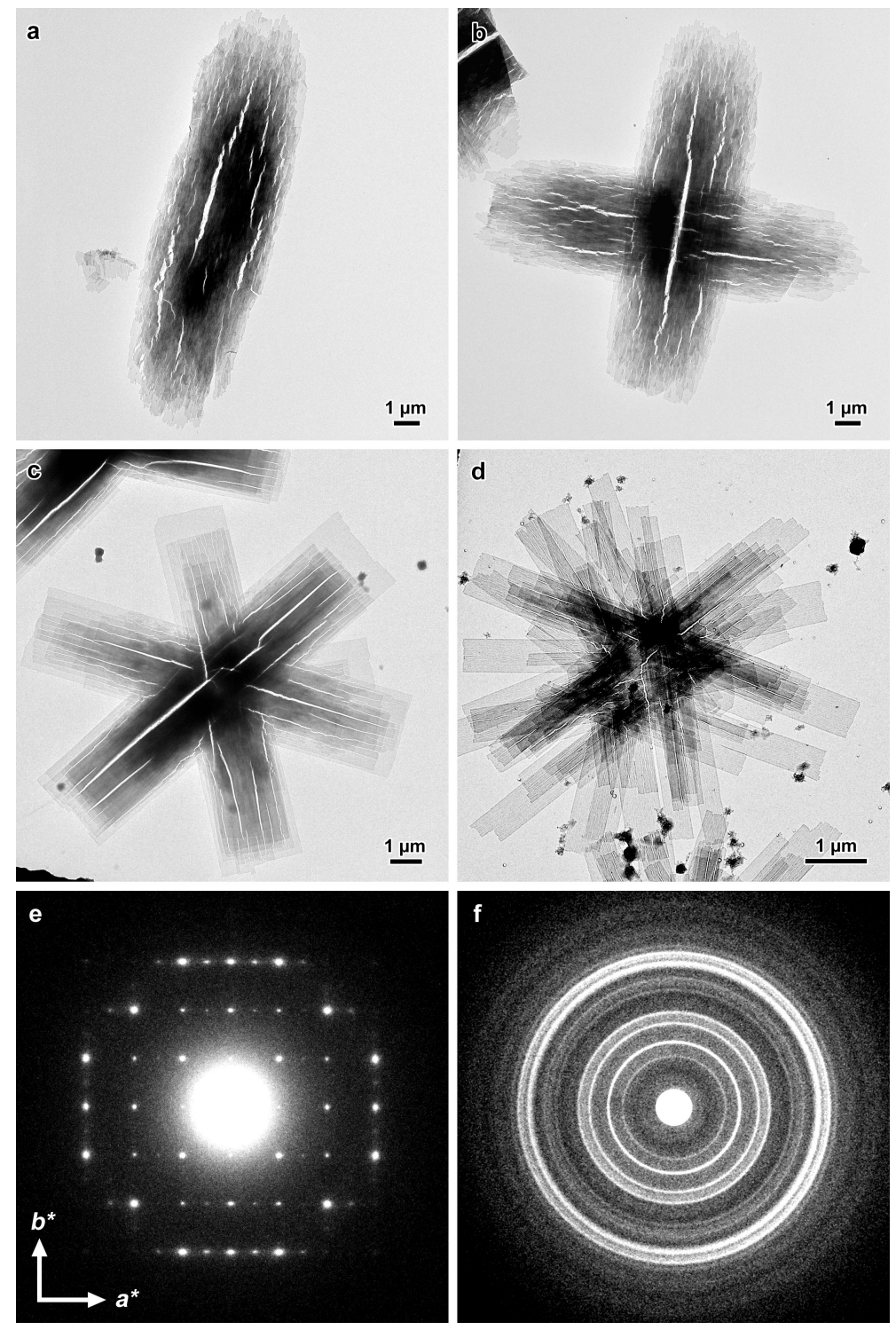

Figure 2. The V6 II structure: a-d) TEM images of crystals of V-amylose crystallized with PENA (a,b), DECA (c) and HEDA (d); e) base-plane ED recorded at low temperature from frozen-hydrated $V_{\text {PENA }}$ crystals; f) powder XRD diagram recorded from $V_{\text {PENA }}$ crystals equilibrated at $95 \% \mathrm{RH}$. 

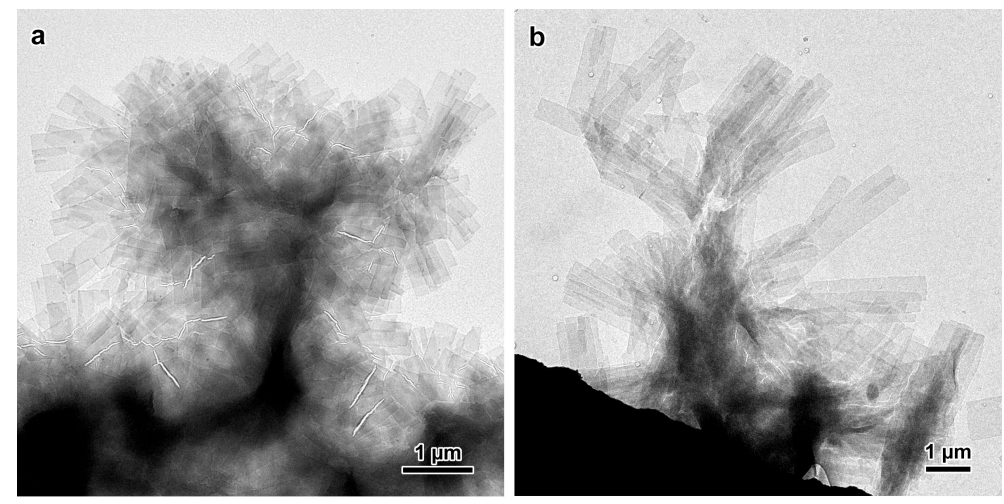

c

d
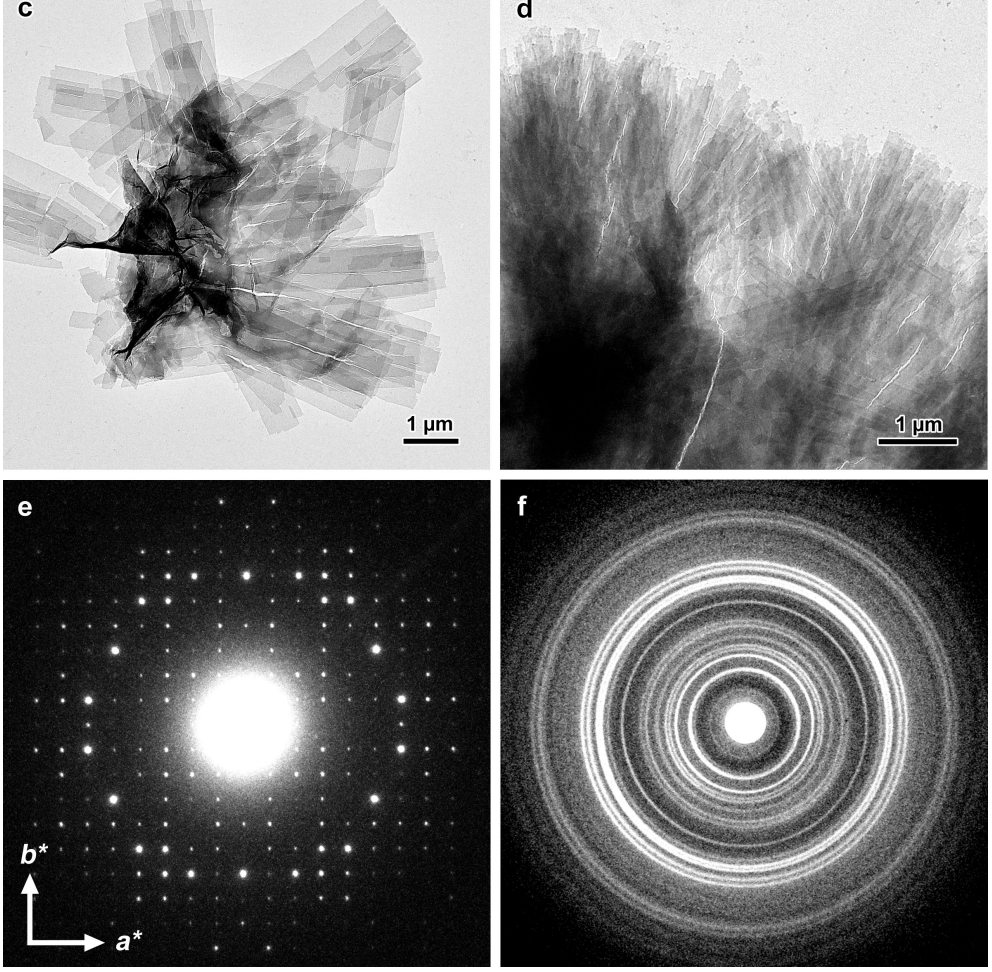

Figure 3. The V7 structure: a-d) TEM images of crystals of V-amylose crystallized with PROA (a), BUTA (b), PENA (c) and DECA (d); e) base-plane ED recorded at low temperature from frozen-hydrated $V_{\text {PENA }}$ crystals; f) powder XRD diagram recorded from $V_{\text {PENA }}$ crystals equilibrated at $95 \% \mathrm{RH}$. 

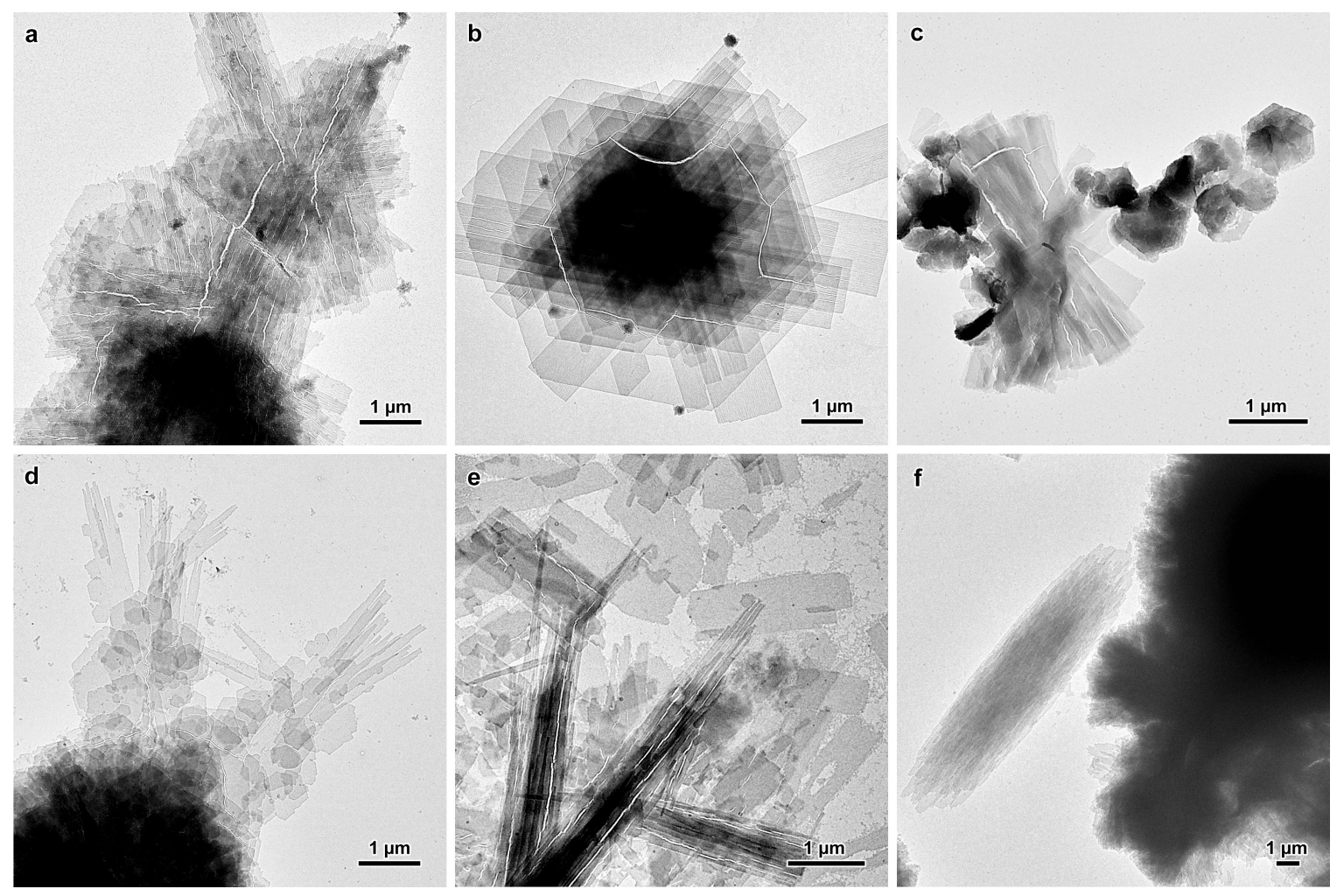

Figure 4. Examples of coexisting crystals with different morphologies and allomorphic types prepared with a given fatty acid: a,b) V6 I and V6 II prepared in water with HEXA (C6) at $50{ }^{\circ} \mathrm{C}$ and TEDA (C14) at $60^{\circ} \mathrm{C}$, respectively, both fatty acids at saturation; c,d) V6 I $_{\text {and }} \mathrm{V} 7$ prepared in the presence of $10 \mathrm{vol} \%$ DMSO with $50 \mathrm{vol} \%$ BUTA (C4) at $60{ }^{\circ} \mathrm{C}$ and OCDA (C18) at $90{ }^{\circ} \mathrm{C}$, respectively; e,f) V6 II and V7 prepared with 5 vol\% BUTA (C4) in water and 3 vol\% PENA (C5) at $40{ }^{\circ} \mathrm{C}$ in the presence of 2 vol\% DMSO, respectively (TEM images). 


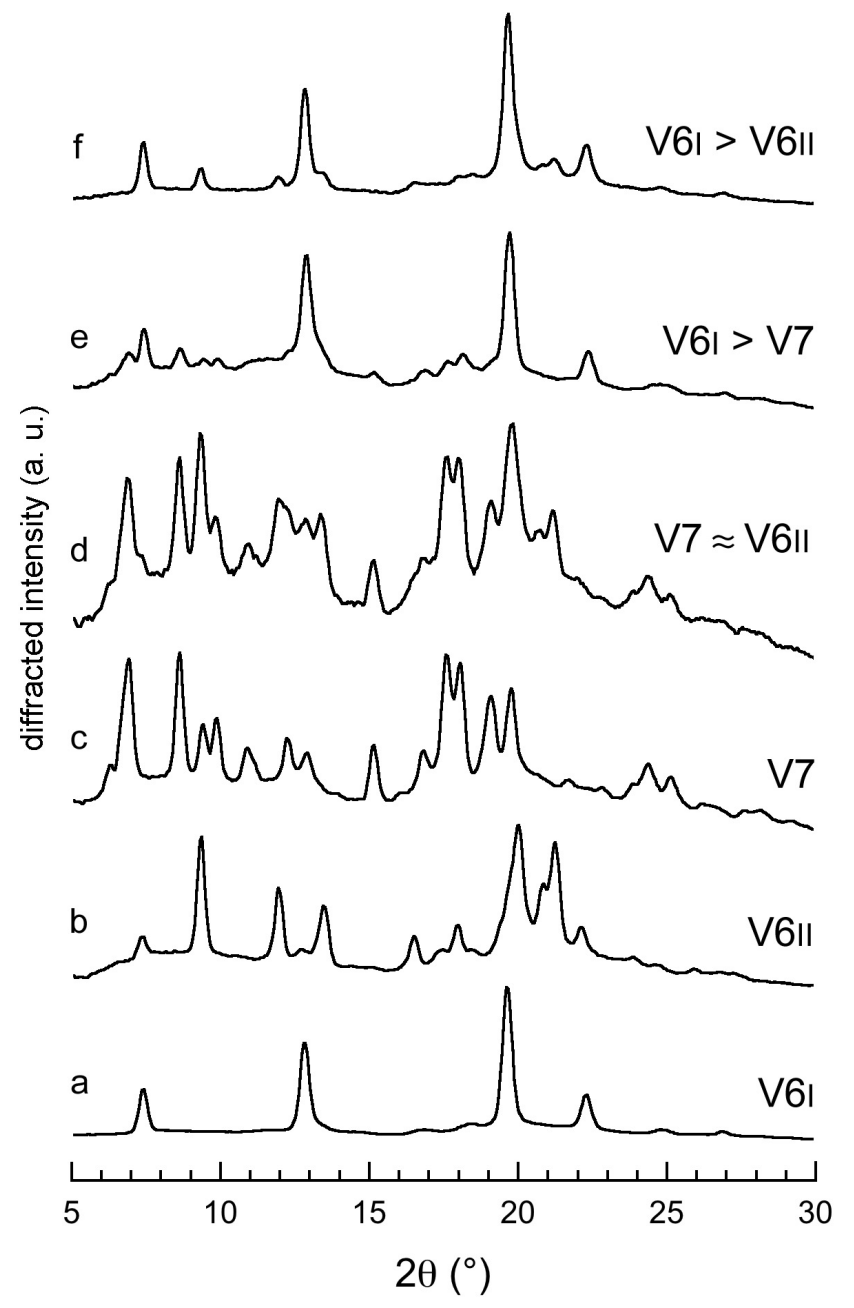

Figure 5. XRD profiles of V-amylose crystallized from aqueous solutions in the presence of a series of linear fatty acids. Unique allomorphs: a) V6 I prepared with TEDA (C14); b) V6 II prepared with HEDA (C16); c) V7 prepared with PENA (C5). Coexisting allomorphs: d) V6 II and V7 prepared with 3 vol\% PENA (C5) at $40{ }^{\circ} \mathrm{C}$ in the presence of 2 vol\% DMSO; e) V6I and V7 prepared in the presence of 2 vol\% DMSO with OCDA (C18) at $90{ }^{\circ} \mathrm{C}$; f) V6 I and V6 II prepared in water with TEDA $(\mathrm{C} 14)$ at $60{ }^{\circ} \mathrm{C}$. The crystals have been equilibrated at $95 \% \mathrm{RH}$. For mixtures (d-f), the major and minor allomorphs are indicated. 

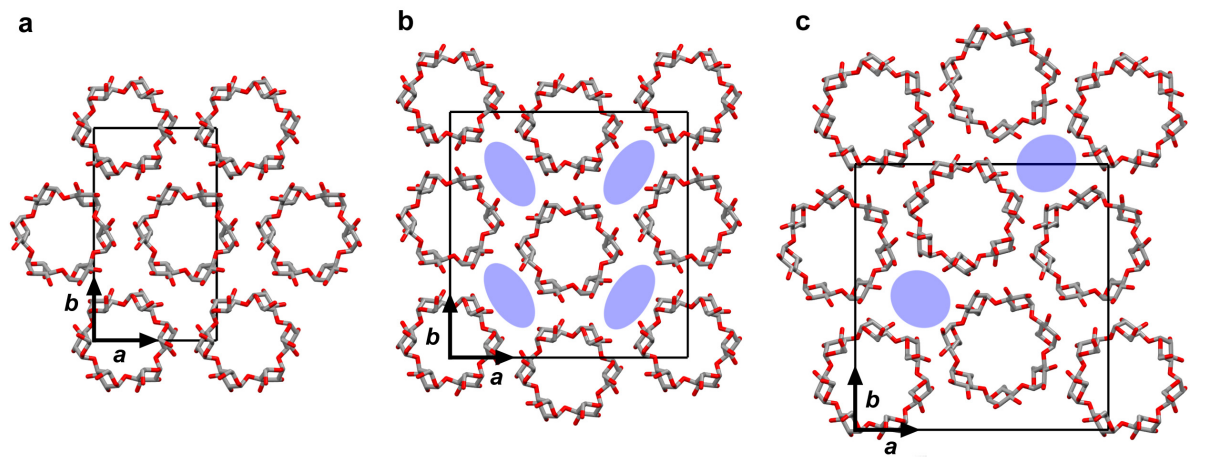

Figure 6. Molecular models of the three allomorphs of V-amylose complexed with fatty acids considered in this study: a) V6 (orthorhombic unit cell), b) V6 II and c) V7. The models are

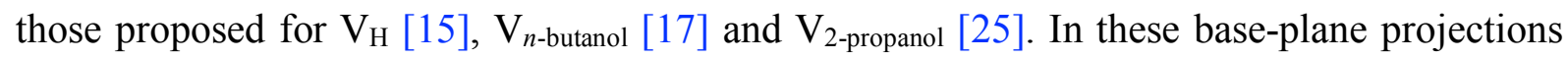
along the helical $c$-axis, only the amylose helices have been drawn. Hydrogen atoms have been removed for clarity. The conformation of the hydroxymethyl group has been fixed as $g g$ in the three cases for simplicity. The blue ovals mark the inter-helical cavities. The unit cells have been superimposed on the models. 


\section{Supplementary Data}

Table S1. Base-plane unit cell parameters of $\mathrm{V} 6_{\mathrm{I}}, \mathrm{V} 6_{\mathrm{II}}$ and $\mathrm{V} 7$ allomorphs determined from ED patterns of single crystals prepared with each fatty acid of the tested series (C3-C20).

\begin{tabular}{c|c|cc|cc}
\hline \multirow{2}{*}{ Fatty acid } & $\mathrm{V}_{\mathrm{I}}{ }^{(\mathrm{a})}$ & \multicolumn{2}{|c|}{$\mathrm{V}_{\mathrm{II}}{ }^{(\mathrm{b})}$} & \multicolumn{2}{|c}{$\mathrm{V}^{(\mathrm{b})}$} \\
\cline { 2 - 6 } & $a=b(\mathrm{~nm})$ & $a(\mathrm{~nm})$ & $b(\mathrm{~nm})$ & $a(\mathrm{~nm})$ & $b(\mathrm{~nm})$ \\
\hline PROA & 1.34 & - & - & - & - \\
BUTA & 1.37 & - & - & 2.83 & $3.00(4)$ \\
PENA & 1.34 & 2.65 & 2.68 & 2.77 & 2.94 \\
HEXA & 1.36 & 2.64 & 2.67 & 2.84 & 2.98 \\
OCTA & 1.39 & - & - & - & - \\
DECA & 1.35 & - & - & 2.88 & 2.94 \\
DODA & 1.37 & - & - & - & - \\
TEDA & 1.36 & - & - & - & - \\
HEDA & 1.36 & - & - & - & - \\
OCDA & 1.36 & - & - & 2.80 & 2.83 \\
ICOA & 1.36 & - & - & - & - \\
\hline Average & $\mathbf{1 . 3 6}$ & $\mathbf{2 . 6 5}$ & $\mathbf{2 . 6 8}$ & $\mathbf{2 . 8 2}$ & $\mathbf{2 . 9 4}$ \\
\hline SD & $\mathbf{0 . 0 2}$ & $\mathbf{0 . 0 1}$ & $\mathbf{0 . 0 1}$ & $\mathbf{0 . 0 3}$ & $\mathbf{0 . 0 7}$ \\
\hline
\end{tabular}

${ }^{a}$ hexagonal unit cell

${ }^{\mathrm{b}}$ orthorhombic unit cell

- : data not available

SD: standard deviation 
Table S2. Unit cell parameters for V6 I (hexagonal), V6 II and V7 (orthorhombic) allomorphs calculated from XRD powder patterns from $\mathrm{V}$-amylose crystals prepared with a series of fatty acids (C3-C20).

\begin{tabular}{c|cc|ccc|ccc}
\hline \multirow{2}{*}{ Fatty acid } & \multicolumn{3}{|c|}{$\mathrm{V6}_{\mathrm{I}}$} & \multicolumn{3}{c|}{$\mathrm{V}_{\mathrm{II}}$} & \multicolumn{3}{c}{$\mathrm{V} 7$} \\
\cline { 2 - 8 } & $a=b(\mathrm{~nm})$ & $c(\mathrm{~nm})$ & $a(\mathrm{~nm})$ & $b(\mathrm{~nm})$ & $c(\mathrm{~nm})$ & $a(\mathrm{~nm})$ & $b(\mathrm{~nm})$ & $c(\mathrm{~nm})$ \\
\hline PROA & 1.37 & 0.82 & - & - & - & 2.80 & 2.97 & - \\
BUTA & 1.36 & 0.80 & - & - & - & 2.79 & 2.96 & 0.80 \\
PENA & 1.38 & 0.80 & 2.63 & 2.69 & 0.82 & 2.81 & 2.98 & - \\
HEXA & 1.37 & 0.81 & 2.65 & 2.71 & 0.81 & - & - & - \\
OCTA & 1.36 & 0.81 & 2.65 & 2.72 & 0.81 & - & - & - \\
DECA & 1.38 & 0.81 & 2.63 & 2.69 & 0.81 & - & - & - \\
DODA & 1.36 & 0.81 & 2.64 & 2.70 & 0.81 & - & - & - \\
TEDA & 1.38 & 0.81 & 2.64 & 2.70 & 0.81 & - & - & - \\
HEDA & 1.37 & 0.82 & 2.63 & 2.69 & 0.81 & - & - & - \\
OCDA & 1.38 & 0.81 & 2.65 & 2.71 & 0.81 & - & - & - \\
ICOA & 1.37 & 0.81 & 2.64 & 2.70 & 0.81 & - & - & - \\
\hline Average & $\mathbf{1 . 3 7}$ & $\mathbf{0 . 8 1}$ & $\mathbf{2 . 6 4}$ & $\mathbf{2 . 7 0}$ & $\mathbf{0 . 8 1}$ & $\mathbf{2 . 8 0}$ & $\mathbf{2 . 9 7}$ & $\mathbf{0 . 8 0}$ \\
\hline SD & $\mathbf{0 . 0 1}$ & $\mathbf{0 . 0 1}$ & $\mathbf{0 . 0 1}$ & $\mathbf{0 . 0 1}$ & $\mathbf{0 . 0 0}$ & $\mathbf{0 . 0 1}$ & $\mathbf{0 . 0 1}$ & - \\
\hline
\end{tabular}

- : data not available

SD: standard deviation 
Table S3. Miller indices, diffraction angles and unit cell parameters for three allomorphs of $V_{\text {PENA }}$ calculated from X-ray diffraction data. The crystals equilibrated at $95 \% \mathrm{RH}$.

\begin{tabular}{|c|c|c|c|c|c|c|c|c|}
\hline \multicolumn{3}{|c|}{$\mathrm{V6}_{\mathrm{I}}{ }^{(\mathrm{a})}$} & \multicolumn{3}{|c|}{$\mathrm{V}_{\text {II }}{ }^{(\mathrm{b})}$} & \multicolumn{3}{|c|}{$\mathrm{V}^{(\mathrm{b})}$} \\
\hline$h k l$ & $2 \theta_{\text {obs }}\left(^{\circ}\right)$ & $2 \theta_{\text {cal }}\left({ }^{\circ}\right)$ & $h k l$ & $2 \theta_{\mathrm{obs}}\left(^{\circ}\right)$ & $2 \theta_{\text {cal }}\left({ }^{\circ}\right)$ & $h k l$ & $2 \theta_{\text {obs }}\left(^{\circ}\right)$ & $2 \theta_{\text {cal }}\left({ }^{\circ}\right)$ \\
\hline 010 & 7.40 & 7.38 & 210 & 7.45 & 7.49 & 110 & 4.38 & 4.32 \\
\hline 110 & 12.84 & 12.80 & 220 & 9.46 & 9.41 & 200 & 6.36 & 6.29 \\
\hline 111 & 16.88 & 16.98 & 320 & 12.11 & 12.06 & 210 & 6.99 & 6.96 \\
\hline 021 & 18.69 & 18.54 & 201 & 12.78 & 12.76 & 220 & 8.72 & 8.65 \\
\hline 120 & 19.65 & 19.61 & 140 & 13.62 & 13.60 & 130 & 9.46 & 9.45 \\
\hline 030 & 22.28 & 22.27 & 430 & 16.67 & 16.73 & 310 & 9.91 & 9.90 \\
\hline 031 & 24.88 & 24.95 & 141 & 17.42 & 17.42 & 230 & 10.93 & 10.91 \\
\hline \multirow[t]{13}{*}{130} & 26.83 & 26.84 & 520 & 18.16 & 18.11 & 140 & 12.28 & 12.29 \\
\hline & & & 160 & 20.15 & 20.11 & 410 & 12.95 & 12.95 \\
\hline & & & 260 & 20.97 & 20.95 & 150 & 15.15 & 15.20 \\
\hline & & & 540 & 21.43 & 21.46 & 520 & 16.88 & 16.87 \\
\hline & & & 360 & 22.28 & 22.29 & 350 & 17.63 & 17.64 \\
\hline & & & 460 & 24.02 & 24.04 & 530 & 18.11 & 18.14 \\
\hline & & & 361 & 24.79 & 24.84 & 610 & 19.16 & 19.19 \\
\hline & & & 560 & 26.13 & 26.13 & 620 & 19.84 & 19.88 \\
\hline & & & & & & 550 & 21.73 & 21.74 \\
\hline & & & & & & 470 & 24.46 & 24.46 \\
\hline & & & & & & 740 & 25.18 & 25.21 \\
\hline & & & & & & 660 & 26.27 & 26.16 \\
\hline & & & & & & 290 & 27.67 & 27.69 \\
\hline
\end{tabular}

${ }^{\mathrm{a}}$ the data were indexed on the basis of a hexagonal unit cell: $a=b=1.383 \pm 0.011 \mathrm{~nm}, c=0.797 \pm$ $0.008 \mathrm{~nm}$. Root-mean-square error (RMSE) $=\sqrt{\sum\left(2 \theta_{\text {obs }}-2 \theta_{\text {cal }}\right)^{2} / N_{\text {reflections }}}=0.072$

${ }^{\mathrm{b}}$ the data were indexed on the basis of an orthorhombic unit cell: $a=2.629 \pm 0.004 \mathrm{~nm}, b=2.688 \pm$ $0.003 \mathrm{~nm}, c=0.817 \pm 0.003 \mathrm{~nm}$. RMSE $=0.035$.

${ }^{\mathrm{c}}$ the data were indexed on the basis of an orthorhombic unit cell with $a=2.808 \pm 0.003 \mathrm{~nm}, b=2.979$ $\pm 0.003 \mathrm{~nm} . \mathrm{RMSE}=0.043$. 

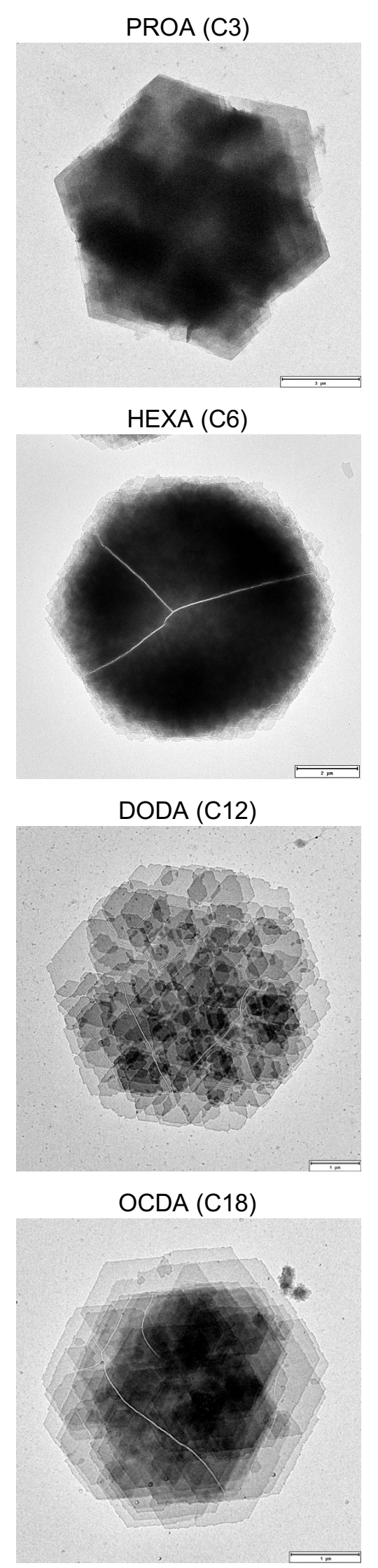
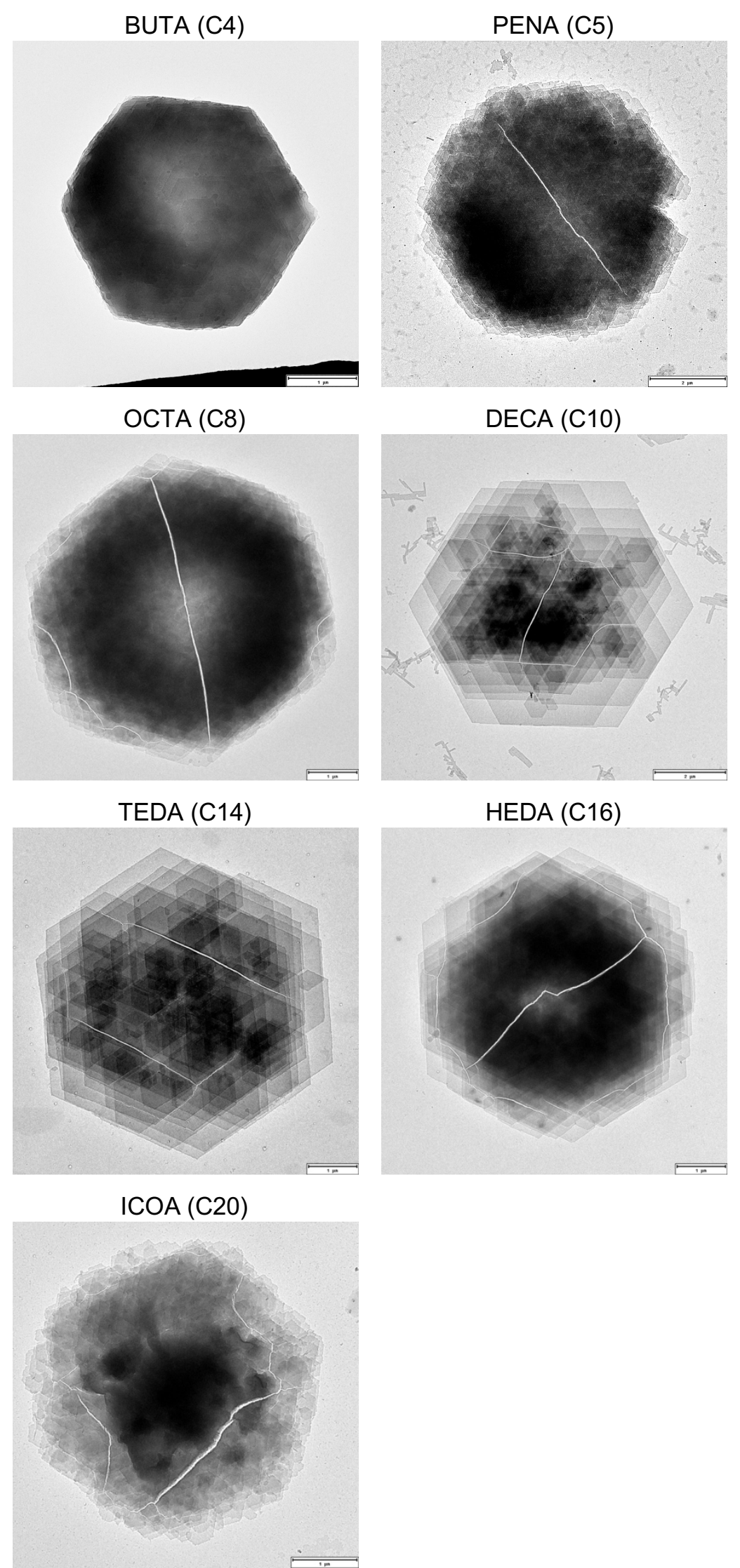

Figure S1. Morphology of $\mathrm{V}_{\text {fatty acid }}$ crystals with a V6 $6_{I}$ structure (TEM images). 


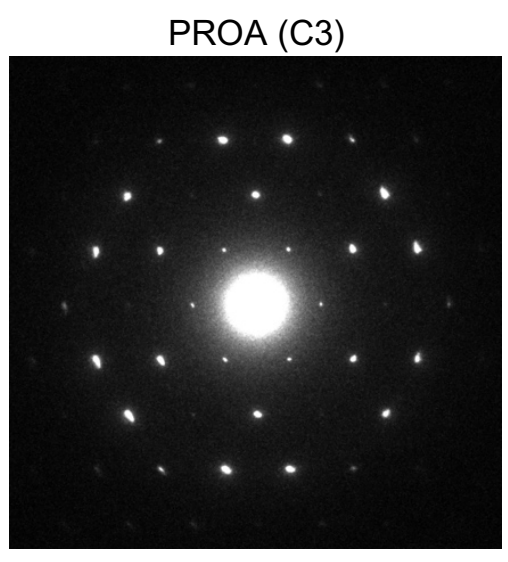

$\operatorname{HEXA}(\mathrm{C6})$

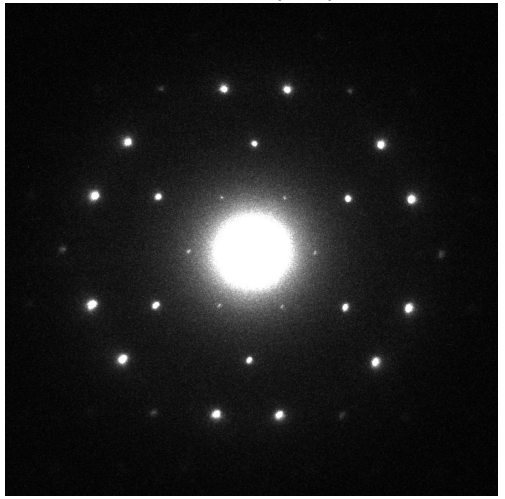

DODA (C12)

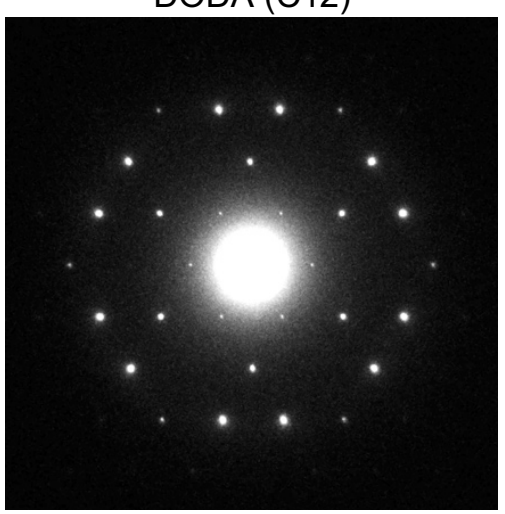

$\operatorname{OCDA}(\mathrm{C} 18)$

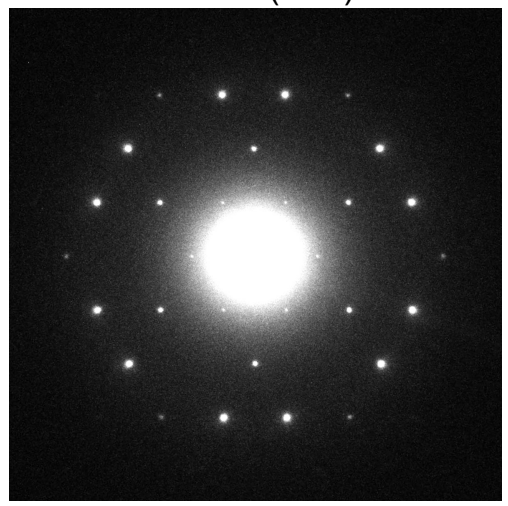

Figure S2. Base-plane electron diffraction patterns of frozen-hydrated $V_{\text {fatty acid }}$ crystals with a V6 $6_{\mathrm{I}}$ structure, recorded at low temperature.

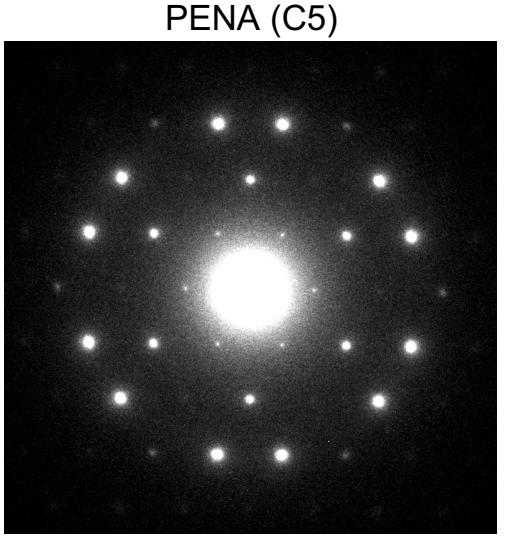

$\operatorname{DECA}(\mathrm{C} 10)$

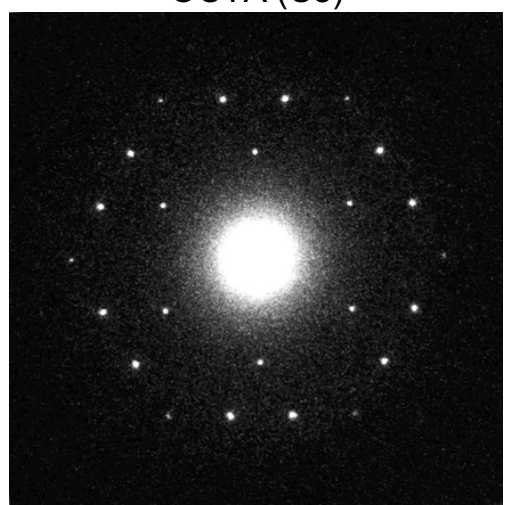

TEDA (C14)

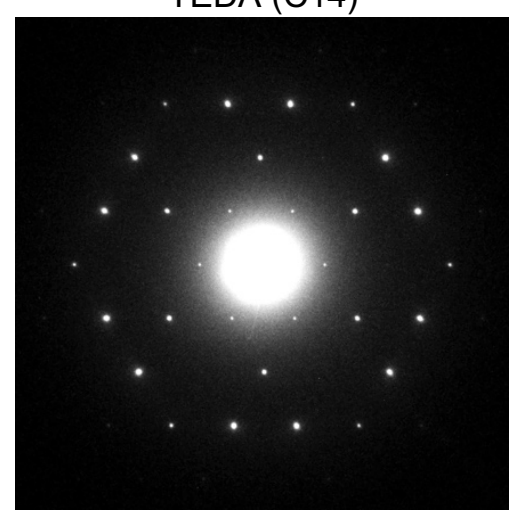

HEDA (C16)

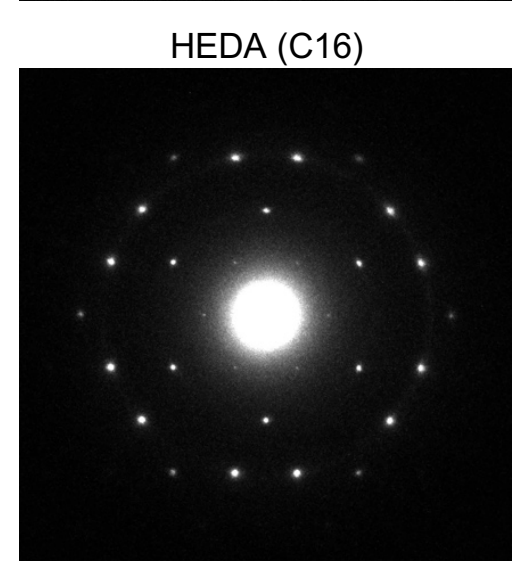

ICOA (C20)
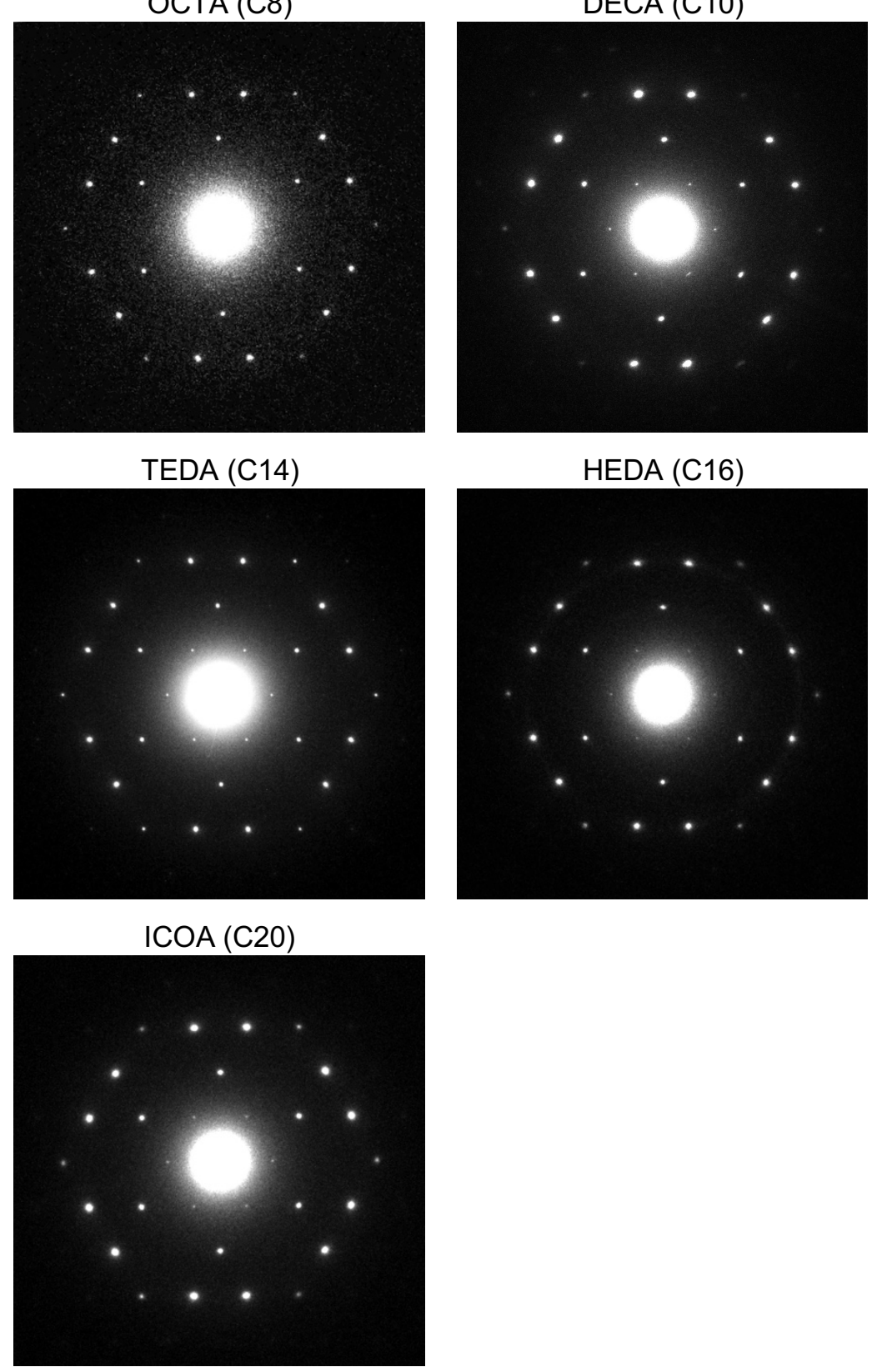


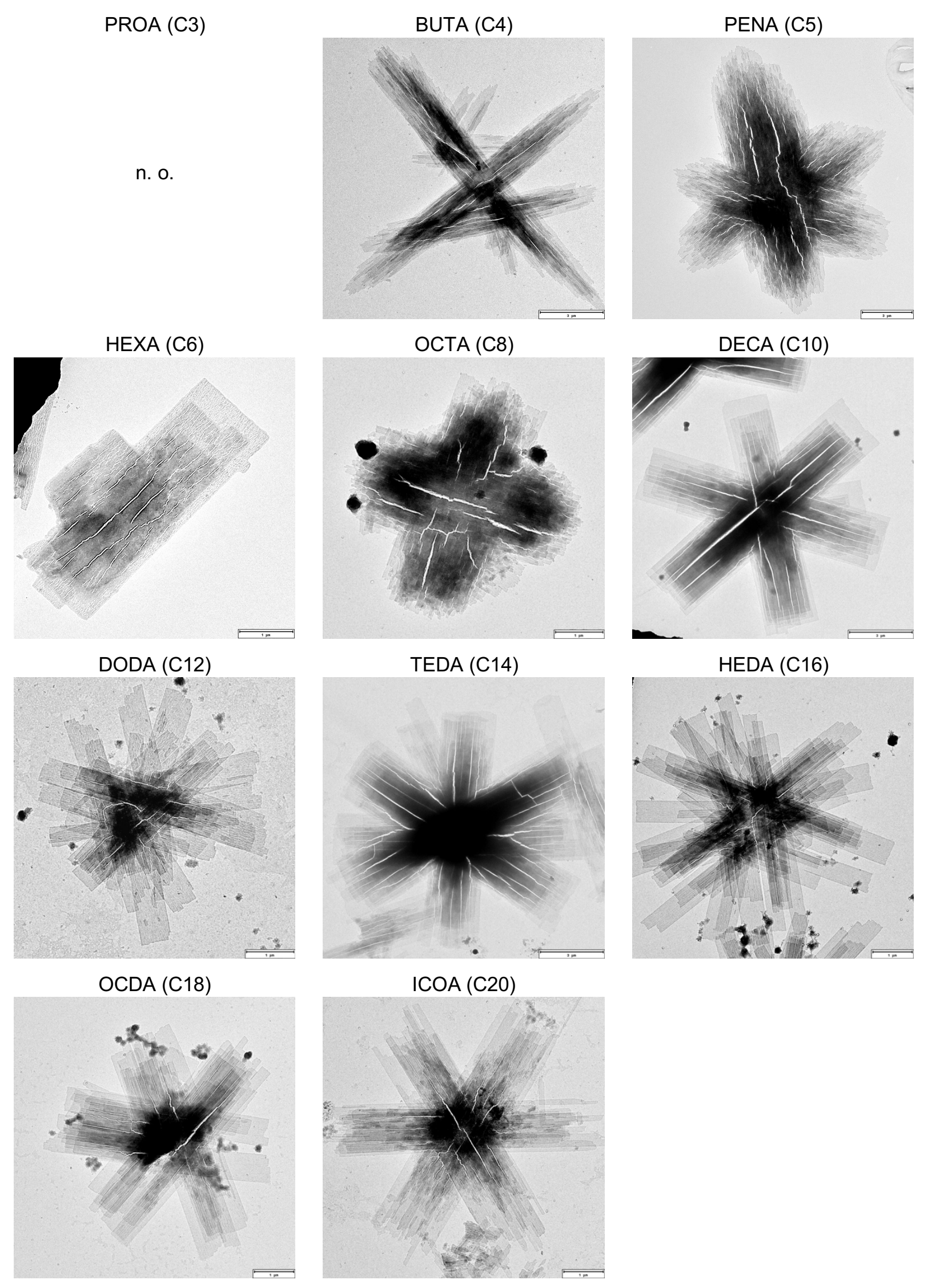

Figure S3. Morphology of lamellar $\mathrm{V}_{\text {fatty acid }}$ crystals with a V6 II structure (TEM images).

"n. o.": not observed. 
PROA (C3)

n. 0 .
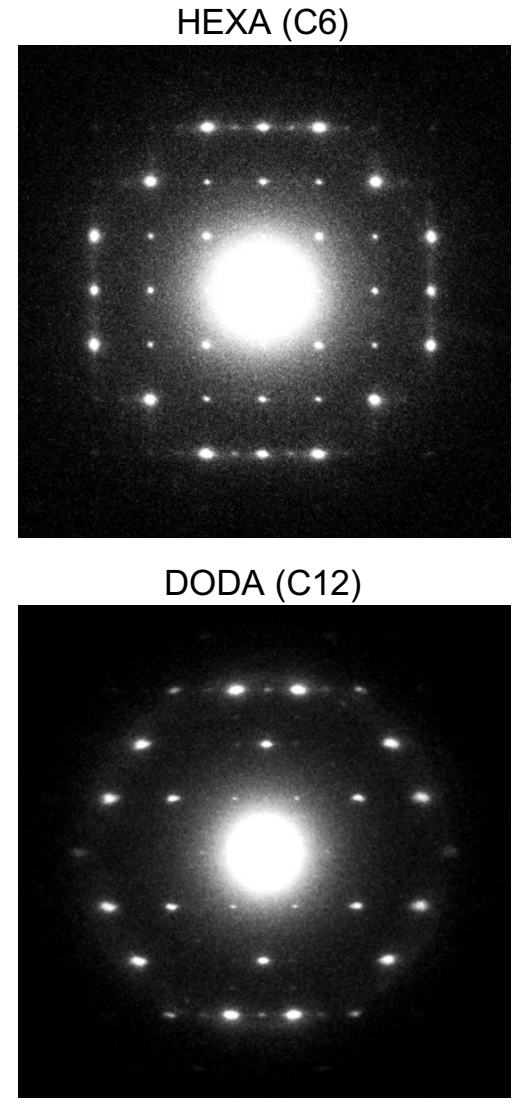

OCDA (C18)
BUTA (C4)

n. r.

n. r.

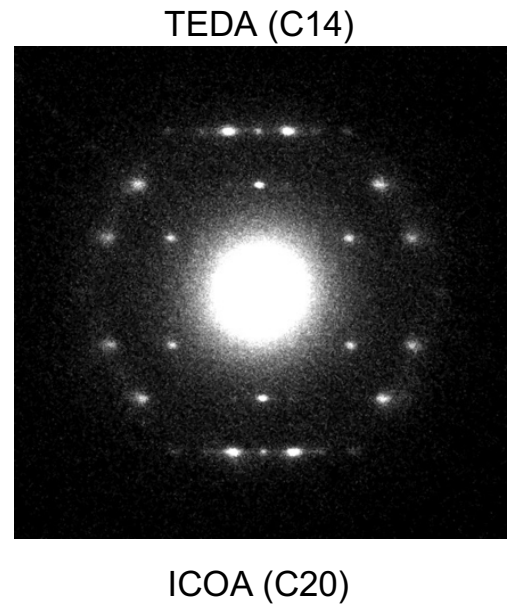

PENA (C5)

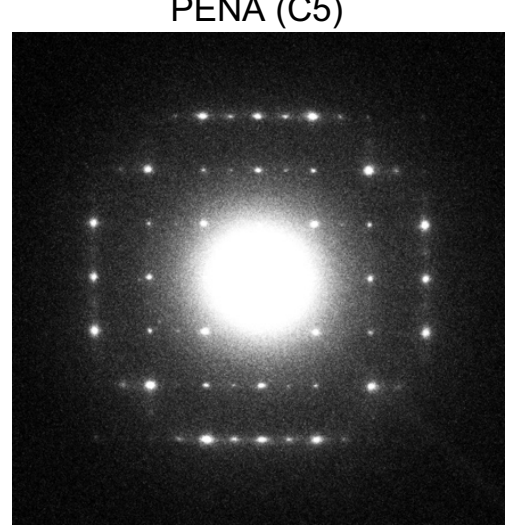

DECA (C10)

HEDA (C16)

n. r.

n. r.

n. r.

n. $r$.

Figure S4. Base-plane electron diffraction patterns of frozen-hydrated $V_{\text {fatty acid }}$ crystals with a V6 $6_{\text {II }}$ structure, recorded at low temperature. "n. o.": not observed; "n. r.": not recorded. The $V_{\text {DODA }}$ and $V_{\text {TEDA }}$ patterns correspond to partially dry crystals that were converting to $\mathrm{V}_{\mathrm{I}}$. 

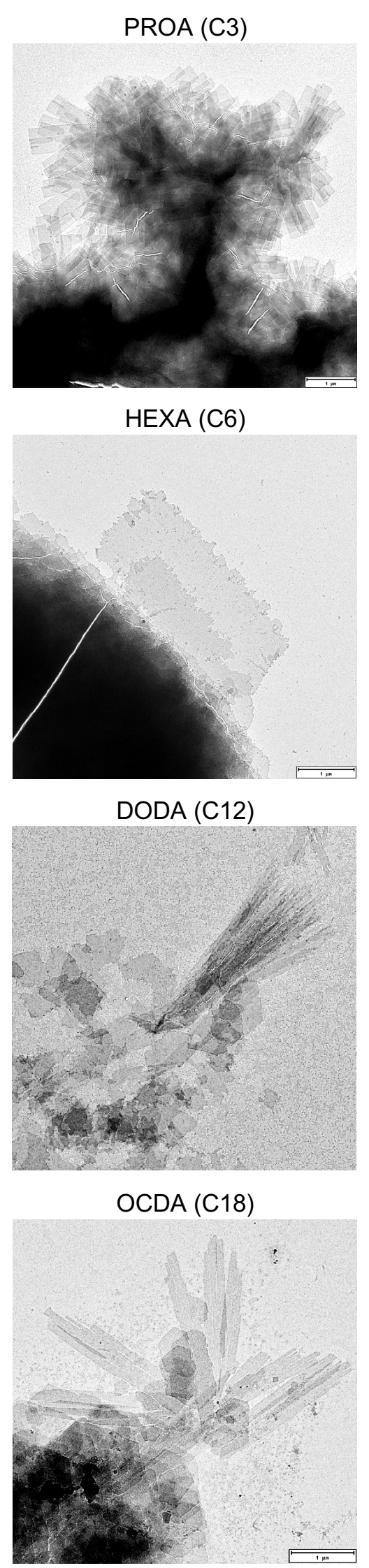

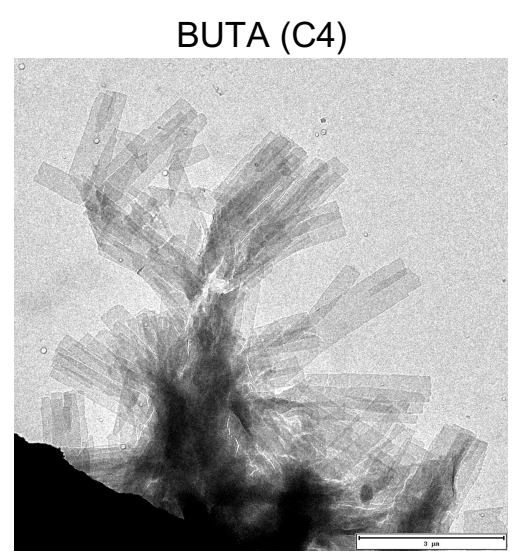

OCTA (C8)

ก. 0 .

ก. 0 .

TEDA (C14)

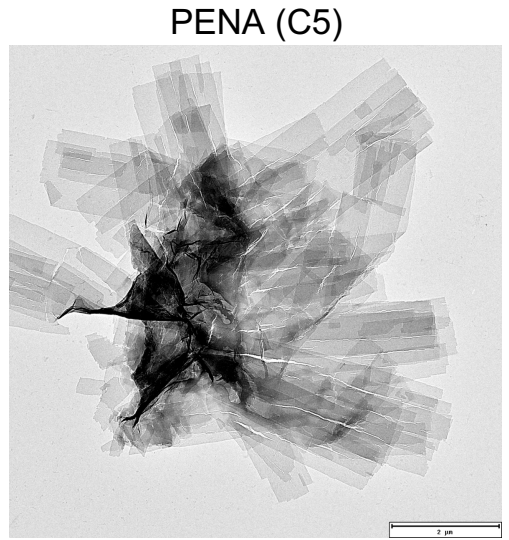

DECA (C10)
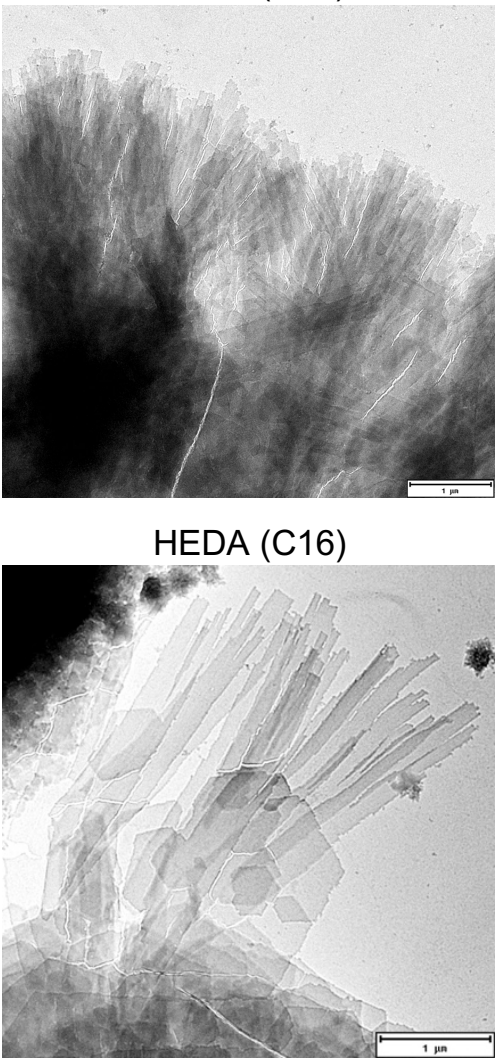

$\operatorname{ICOA}(\mathrm{C} 20)$

n. 0 .

Figure S5. Morphology of lamellar $\mathrm{V}_{\text {fatty acid }}$ crystals with a V7 structure (TEM images).

"n. o.": not observed. 
PROA (C3)

n. 0 .

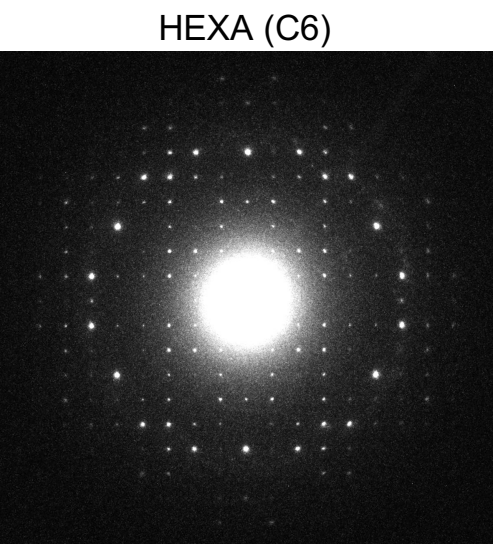

DODA (C12)

n. o.

OCDA (C18)

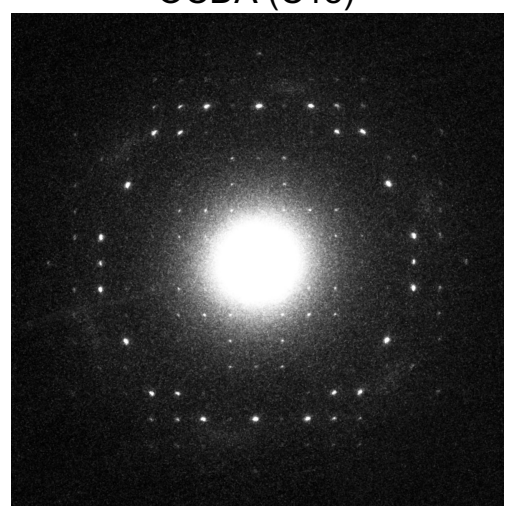

BUTA (C4)

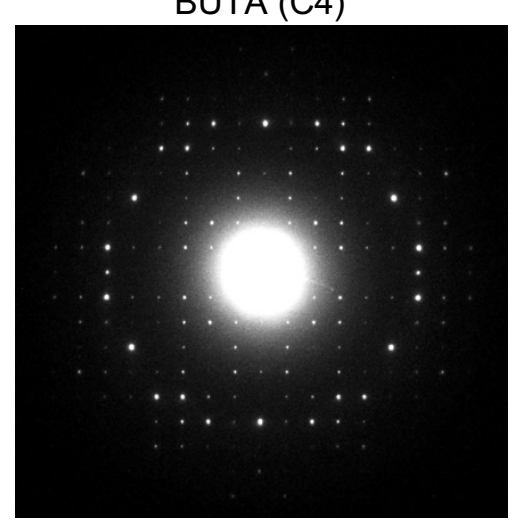

OCTA (C8)

n. 0.

TEDA (C14)

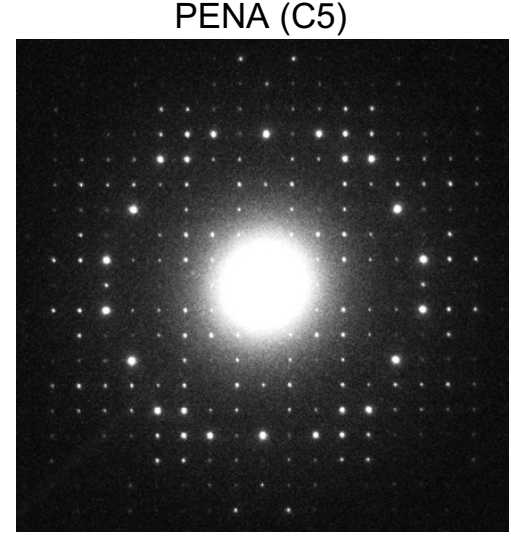

DECA (C10)

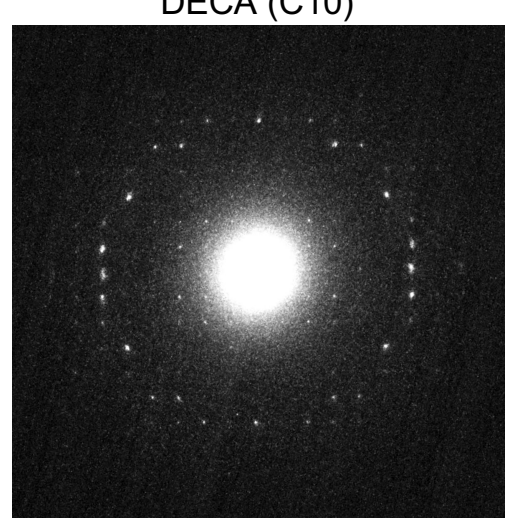

HEDA (C16)

n. 0 .

n. 0.

ICOA (C20)

n. o.

Figure S6. Base-plane electron diffraction patterns of frozen-hydrated $V_{\text {fatty acid }}$ crystals with a V7 structure, recorded at low temperature. "n. o.": not observed. 
a

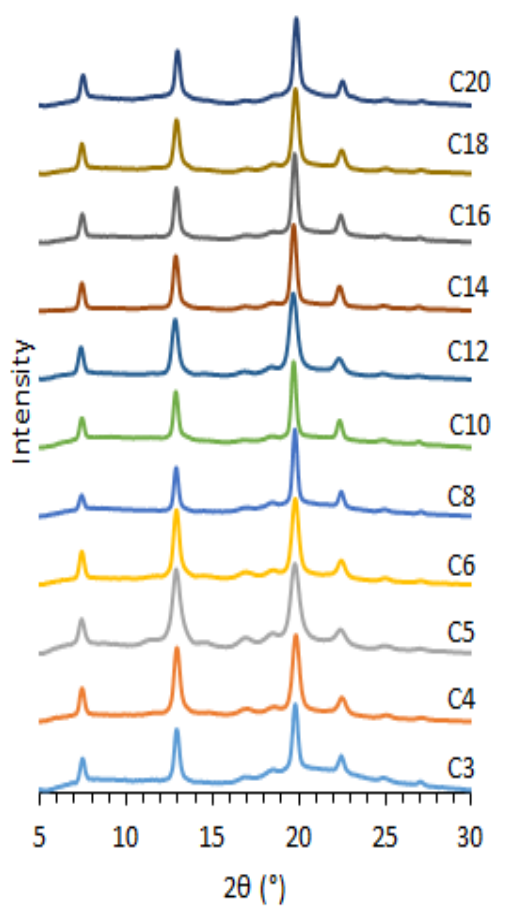

b

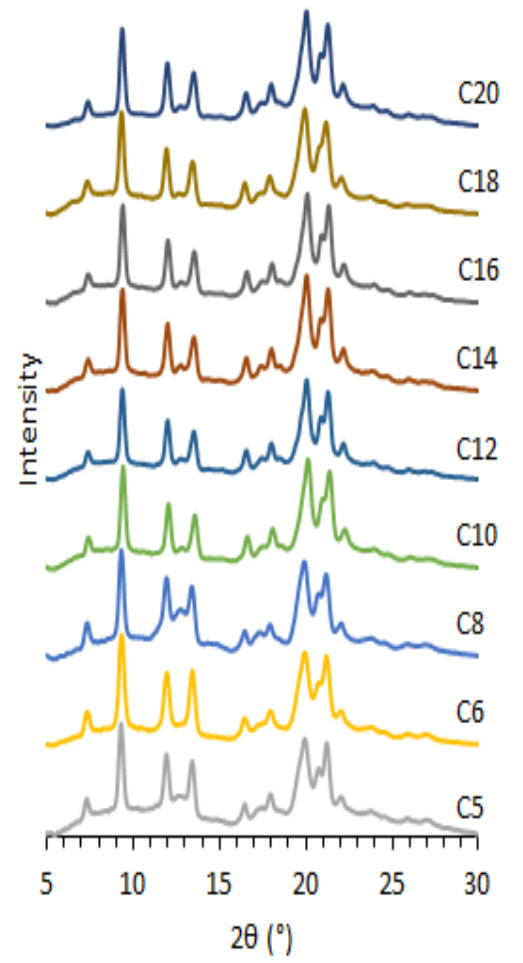

C

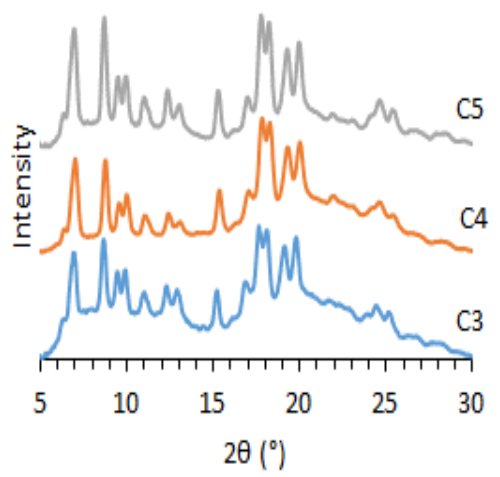

Figure S7. XRD profiles of V-amylose crystallized from aqueous solutions in the presence of a series of linear fatty acids (C3-C20). The crystals have been equilibrated at 95\% RH. The corresponding allomorphs are $\mathrm{V} 6_{\mathrm{I}}(\mathrm{a}), \mathrm{V} 6_{\text {II }}$ (b) and $\mathrm{V} 7$ (c). Only diffraction profiles corresponding to individual allomorphs are presented. 

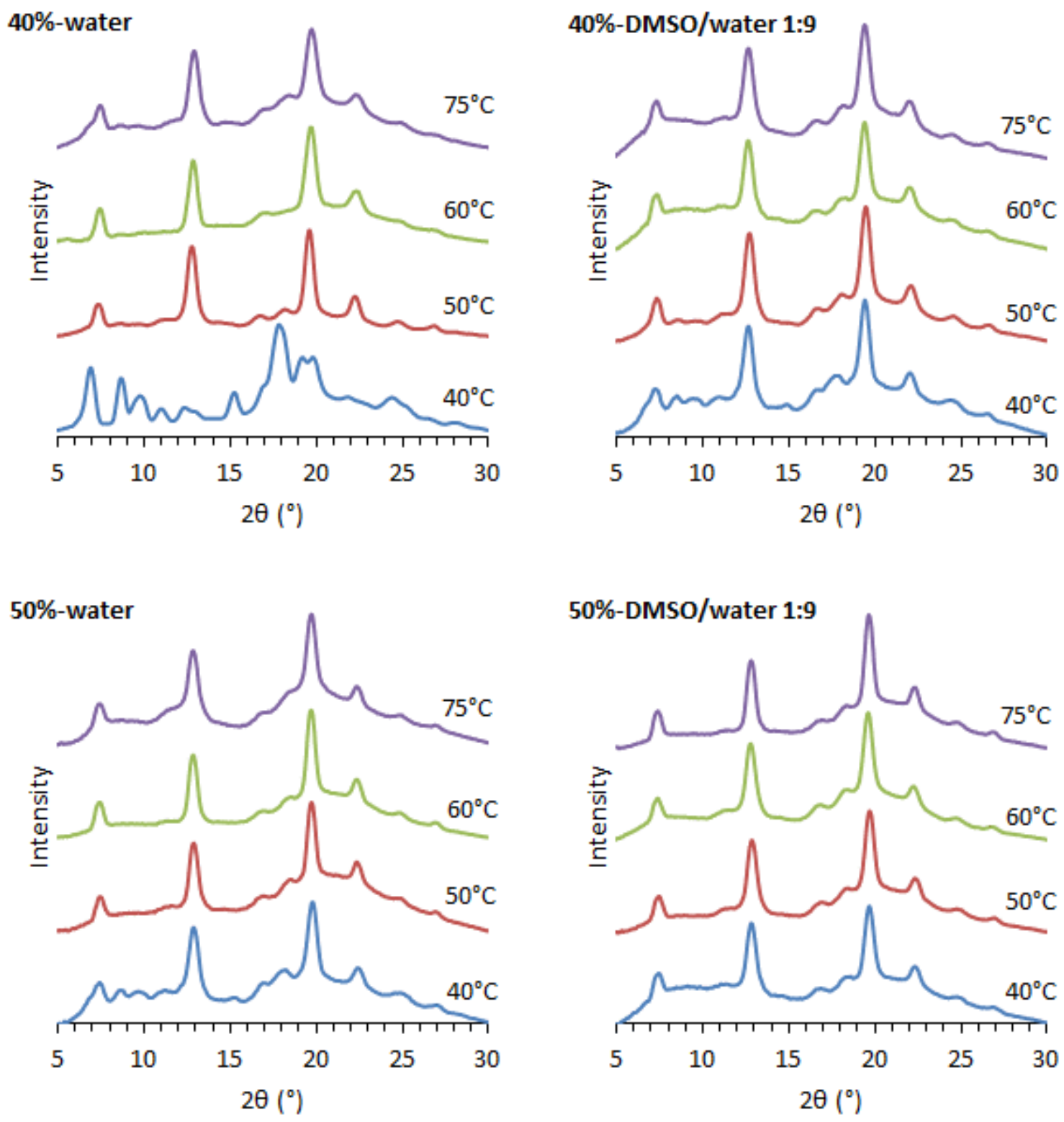

Figure S8. $X R D$ profiles of $V_{P R O A}(C 3)$ complexes prepared at different temperatures in the presence of 40 and $50 \mathrm{vol} \%$ of PROA in pure water or in a 1:9 DMSO:water mixture. 

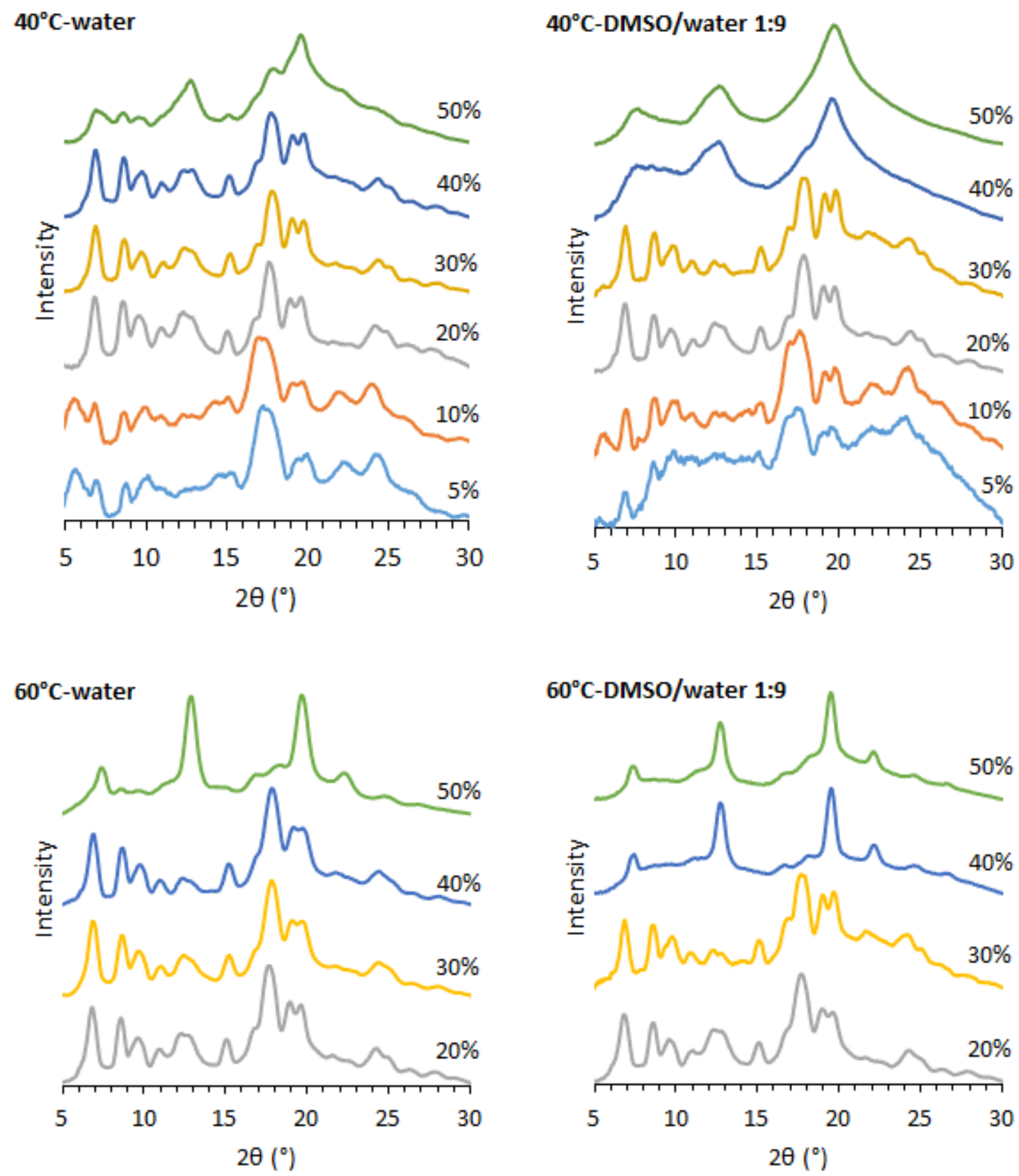

Figure S9. XRD profiles of $\mathrm{V}_{\text {BUTA }}(\mathrm{C} 4)$ complexes prepared with different concentrations of BUTA in pure water or in a 1:9 DMSO:water mixture, at 40 and $60{ }^{\circ} \mathrm{C}$. 

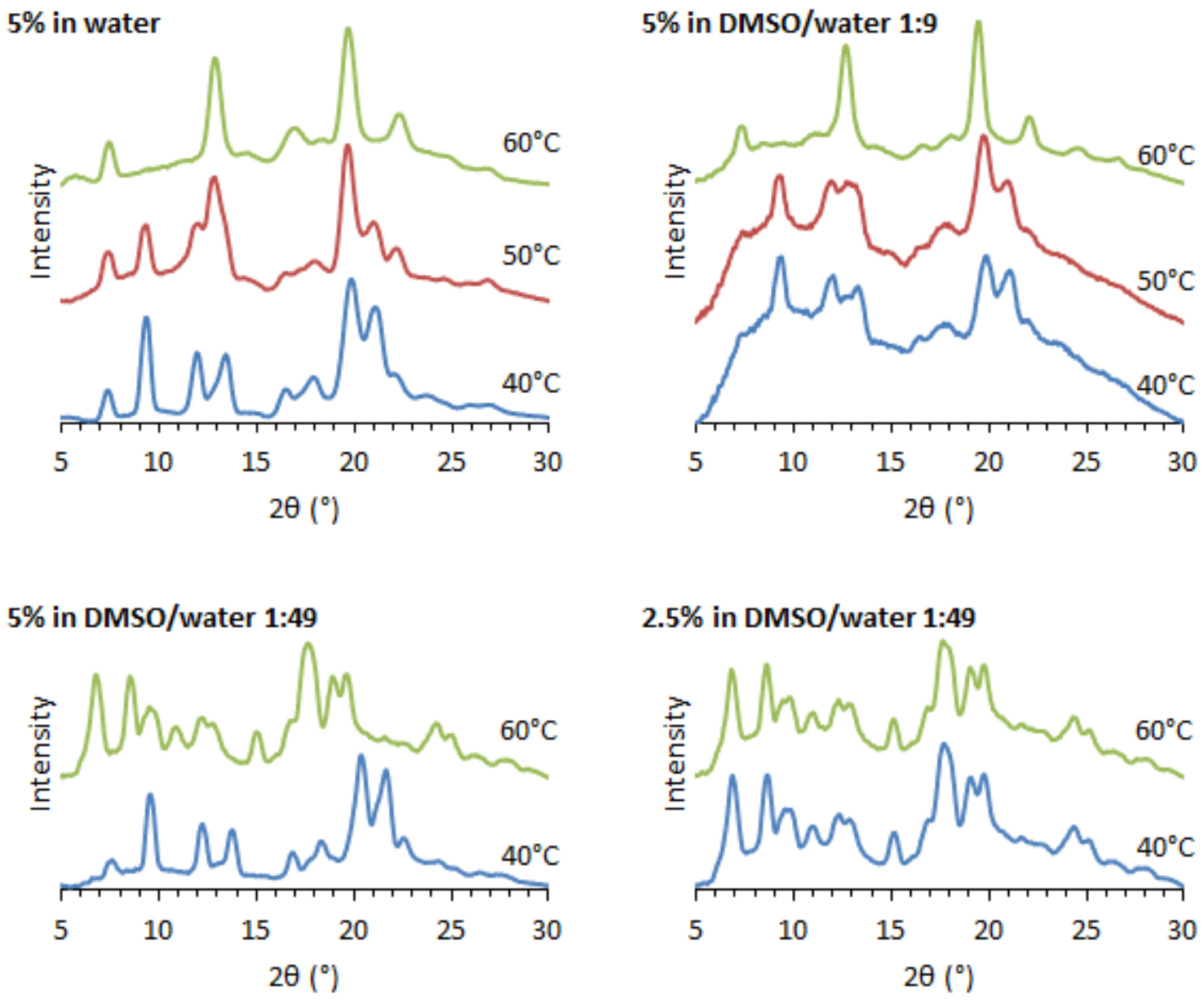

Figure S10. XRD profiles of $\mathrm{V}_{\mathrm{PENA}}(\mathrm{C} 5)$ prepared in pure water and in a 1:9 or 1:49 DMSO:water mixture at different temperatures and concentrations of PENA. 

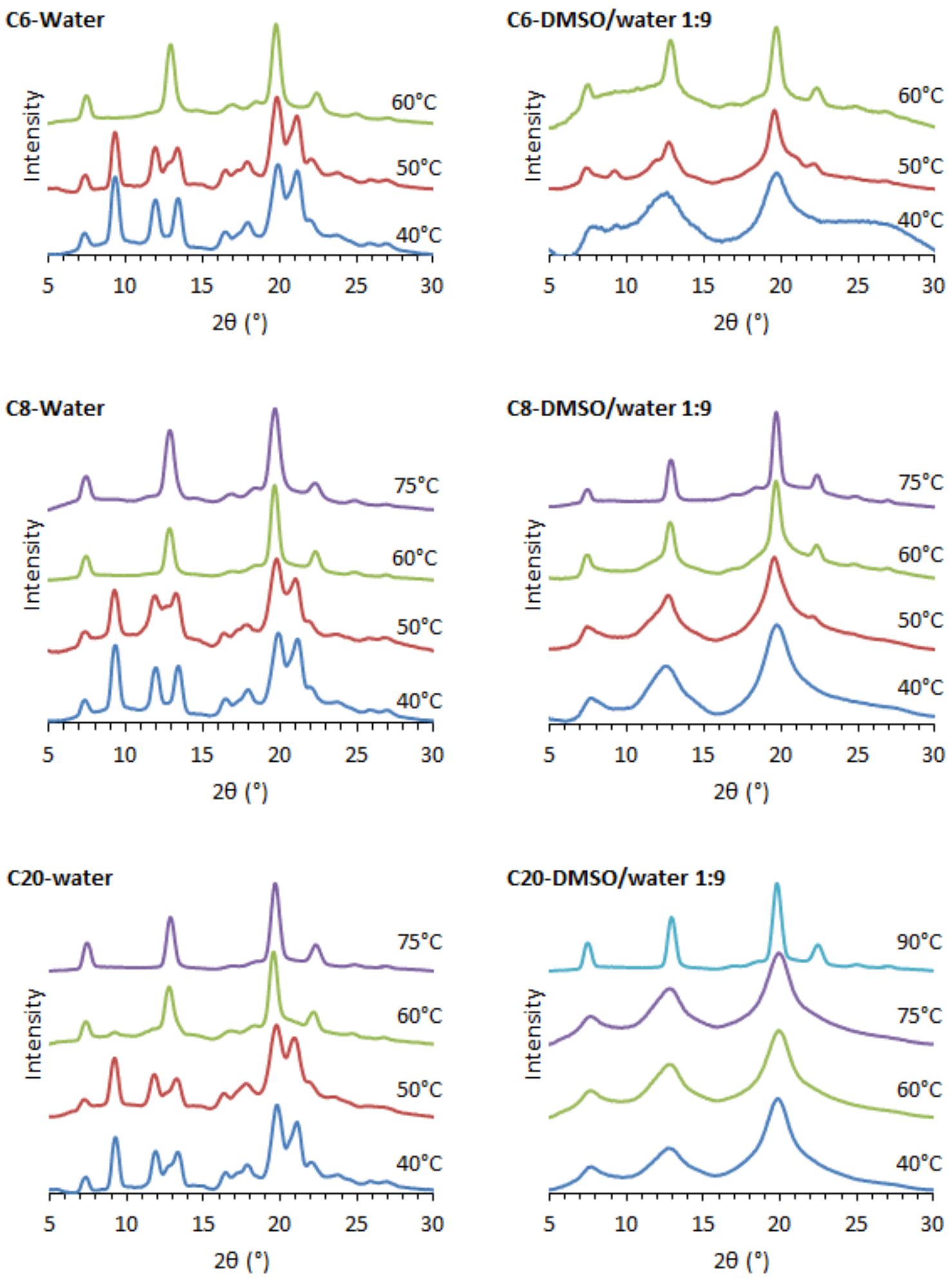

Figure S11. XRD profiles of $\mathrm{V}_{\mathrm{HEXA}}(\mathrm{C} 6), \mathrm{V}_{\text {OCTA }}(\mathrm{C} 8)$ and $\mathrm{V}_{\text {ICOA }}(\mathrm{C} 20)$ prepared at different temperatures in pure water and in a 1:9 DMSO:water mixture. 